\title{
Predicting rectal temperature and respiration rate responses in lactating dairy cows exposed to heat stress
}

\author{
Gan Li, (1) Siyu Chen, (1) Jian Chen, Dandan Peng, (D) and Xianhong Gu* (i) \\ State Key Laboratory of Animal Nutrition, Institute of Animal Science, Chinese Academy of Agricultural Sciences, Beijing 100193, P. R. China
}

\begin{abstract}
Milk production and time effects are considered related to heat stress but they have not yet been combined in predictive models. In two parts, this study aimed to develop new models to predict heat stress (rectal temperature and respiration rate) of lactating dairy cows by inputting predictors, including ambient temperature $\left(\mathrm{T}_{\mathrm{a}}\right)$, relative humidity $(\mathrm{RH})$, wind speed (WS), milk yield (MY), and time blocks. In the first part of the study, we built the quantitative foundation for the second part, including the regression relation between respiration rate and rectal temperature (to convert predicted respiration rate to predicted body temperature), as well as between rectal temperature and respiration rate when heat stress was triggered (to recognize whether herds were under stress). In the second part, we built models that combined the abovementioned predictors to predict respiration rate. In part I, data were obtained from 45 high-producing Holstein cows within a $\mathrm{T}_{\mathrm{a}}$ range of 9.5 to $30.8^{\circ} \mathrm{C}$. We found a very strong correlation between mean respiration rate (MRR) and mean rectal temperature (MRT), where $\mathrm{MRT}=0.021 \times \mathrm{MRR}+37.6\left(\mathrm{R}^{2}=0.925\right)$, suggesting that for each 4.8 breaths per minute (bpm) increase of MRR, MRT would be expected to increase by $0.1^{\circ} \mathrm{C}$. Rectal temperature was determined to be $38.6^{\circ} \mathrm{C}$ when heat stress was triggered, which corresponded to a respiration rate of $48 \mathrm{bpm}$. In part II, data were obtained in 3 stalls within a $\mathrm{T}_{\mathrm{a}}$ range of 6.9 to $33.3^{\circ} \mathrm{C}$ over 3 time blocks, all of which were the 90 min preceding milking (0630-0800, 1230-1400, and 1830-2000 h). We found a nonlinear response of MRR to $T_{a}$, which could be linearized by the quadratic term of $T_{a}$. The response of MRR was the highest in the $0630-0800 \mathrm{~h}$ block, followed by $1230-1400 \mathrm{~h}$, and finally $1830-2000 \mathrm{~h}$. We proposed a model combining 3 time blocks $\left(\mathrm{R}^{2}=0.836\right)$ : $\mathrm{MRR}$ in
\end{abstract}

Received January 31, 2019.

Accepted February 4, 2020.

*Corresponding author: guxianhong@vip.sina.com
0630-0800 h was determined to $56.28+(-3.40+0.11$ $\left.\times \mathrm{T}_{\mathrm{a}}+0.02 \times \mathrm{RH}\right) \times \mathrm{T}_{\mathrm{a}}-0.21 \times \mathrm{RH}-2.82 \times \mathrm{WS}$ $+0.62 \times$ MY; MRR in 1230-1400 h and 1830-2000 h were 4.6 and $10.3 \mathrm{bpm}$ lower than that in $0630-0800 \mathrm{~h}$, respectively (reducing the intercept of the expression in 0630-0800 h). Compared with temperature-humidity index equations, the proposed model performed better at suppressing prediction error, and had better sensitivity and accuracy in recognizing whether heat stress was triggered.

Key words: dairy cow, heat stress, predictive model, thermal environment factor

\section{INTRODUCTION}

Cooling strategies to reduce the heat stress of lactating dairy cows have long been a central issue in dairy production loss and animal welfare (Collier et al., 1981, 2017; Spiers et al., 2004). Cooling strategies should be made according to the magnitude of heat stress (Hahn et al., 2003; Spiers et al., 2018; Tresoldi et al., 2018). To estimate this magnitude, many predictive models have been developed in the past $70 \mathrm{yr}$. The most widely used predictive model is temperature-humidity index (THI), which combines effects of temperature and humidity (Thom, 1959; West, 2003). However, THI does not entirely represent the thermal environment (Collier and Zimbelman, 2007; Gaughan et al., 2008). Over the last 2 decades, studies have attempted to combine other environmental factors such as airflow and solar radiation to improve the predictive accuracy of THI alone. For instance, the index of thermal stress for cows (ITSC) and equivalent temperature index (ETIC) were developed for dairy cattle (Da Silva et al., 2015; Wang, et al., 2018); and heat load index (HLI), comprehensive climate index (CCI), and respiration rate models have been created for beef cattle (BrownBrandl et al., 2005a; Gaughan et al., 2008; Mader et al., 2010). Nonparametric algorithms have been created to improve the predictive effect of environment factors (Hernández-Julio et al., 2014; Sousa et al., 2016). Environmental factors have explained 5 to $72 \%$ of total variance of heat stress response (e.g., body tempera- 
ture or respiration rate) using different algorithms (de Andrade Ferrazza et al., 2017; Wang et al., 2018). But part of the variance remains that is difficult to explain by environment factors using both parametric and nonparametric algorithms. The unexplained variance could be related to other stress-related factors, such as coat characteristics, maximum evaporative capacity, feed intake, and milk production (Berman, 2005; Collier et al., 2011; Collier and Gebremedhin, 2015). Thus, inputting the abovementioned factors is likely to improve the predictive accuracy of an index.

Of the abovementioned factors, milk production seems the most readily available because it can be acquired directly from an automatic milking system. There is a positive correlation between heat stress response and milk production (Kadzere et al., 2002; Berman, 2003; Collier and Gebremedhin, 2015): high-producing cows are considered more susceptible to ambient heat (Carabaño et al., 2014). High-producing cows are reported to have a higher body temperature than low-producing cows (Barash et al., 2001; Yano et al., 2014). Moreover, the threshold temperature for the onset of heat stress was $5^{\circ} \mathrm{C}$ lower for cows producing $45 \mathrm{~kg} / \mathrm{d}$ of milk than for cows producing $35 \mathrm{~kg} / \mathrm{d}$ (Berman, 2005). It seems feasible that prediction accuracy could be improved by including milk production as a predictor.

Another notable stress-related factor is the effect of time blocks of day. Relationships between environment factors and heat stress are not identical in different time blocks of the day (Igono and Johnson, 1990; Vickers et al., 2010; Atkins et al., 2018). For instance, body temperature increases even if ambient temperature decreases in the morning (Vickers et al., 2010). From the perspective of prediction, it seems simple and practicable to input time blocks as a predictor.

In previous studies, rectal temperature was used as a gold standard of heat stress (Berman et al., 1985; Dikmen and Hansen, 2009; Wang et al., 2018). Under farm conditions, respiration rate is commonly used instead because measuring it is less disruptive to cows (Gaughan et al., 2000; Eigenberg et al., 2003; BrownBrandl et al., 2005b). Respiration rate data can be converted to rectal temperature because of the positive correlation between them (Hales and Findlay, 1968; McArthur, 1987; McGovern and Bruce, 2000). Thus, we used respiration rate as a response variable to build the predictive models in this study. The respiration rate in the predictive models can be further converted to predicted rectal temperature. However, the reported correlation coefficients between respiration rate and rectal temperature are quite variable in previous reports. For instance, Collier and Zimbelman (2007) reported a strong correlation $(\mathrm{r}=0.75)$ between respira- tion rate and rectal temperature, much higher than the moderate correlation $(\mathrm{r}=0.55)$ reported by Martello et al. (2010) and the very low correlation $(\mathrm{r}=0.046)$ reported by Kabuga (1992). Therefore, it is necessary to reassess the regression relationship between respiration rate and rectal temperature before establishing predictive models.

In part I of this study, we established the regression relationship between respiration rate and rectal temperature. Furthermore, we determined normal rectal temperatures and respiration rates as the basis for recognizing stress state (i.e., whether stress was triggered or not) of herds. In part II, we built the predictive models to predict the respiration rate of herds using ambient temperature, relative humidity, wind speed, time blocks, and milk yield. Models with good predictive performance, interpretability, and parsimony are proposed. In addition, we compared the prediction accuracy and performance on recognizing the stress state of the proposed models with that using THI.

\section{MATERIALS AND METHODS}

All procedures were approved by the Chinese Academy of Agricultural Sciences Animal Care and Use Committee. This study was carried out from July to October 2016 in a Holstein dairy farm located in northeast Beijing. The area of each stall was $14 \mathrm{~m} \times 100$ $\mathrm{m}$. The roof structure covered the total area of stall so most of direct solar radiation was prevented from reaching the surface of cows during the day. Cows were milked 3 times a day at 0800-1100, 1400-1700, and 2000-2300 h. Cow information, including daily milk yield (MY, kg/d), DIM, and parity, was acquired from the automatic milking system. Rectal temperatures were recorded manually using a digital GLA M750 thermometer (GLA Agricultural Electronics, San Luis Obispo, CA); respiration rates were determined as the time of 10 flank movements and converted to breaths per minute (bpm). The measurements of respiration rate and rectal temperature for each cow were taken at least twice, and the 2 replicates were averaged. The measurements of environment factors - ambient temperature $\left(\mathbf{T}_{\mathbf{a}},{ }^{\circ} \mathrm{C}\right)$, relative humidity $(\mathbf{R H}, \%)$, and wind speed (WS, m/s) - were conducted using Kestrel 5000 environment meters (Nielsen-Kellerman Co., Boothwyn, PA). The environment meters were mounted $2 \mathrm{~m}$ above the ground on the center pillars of stalls. The recording frequency for the environment meters was $5 \mathrm{~min}$. The environment meters were placed at 3 locations in each observed stall, at one-fourth, one-half, and three-fourths of the length of the stall. The environment factors that were input into regres- 
Table 1. Summary of the cows' information of observed stalls on test days (study part II) ${ }^{1}$

\begin{tabular}{|c|c|c|c|c|c|c|}
\hline Information & \multicolumn{2}{|c|}{ Stall 1} & \multicolumn{2}{|c|}{ Stall 2} & \multicolumn{2}{|c|}{ Stall 3} \\
\hline Parity & $2.8(0.06)$ & $2.7-2.9$ & $2.1(0.12)$ & $2.0-2.5$ & $2.3(0.09)$ & $2.1-2.5$ \\
\hline Milk yield, kg/d & $34.7(2.2)$ & $30.6-38.5$ & $29.9(1.7)$ & $26.5-32.6$ & $18.3(0.9)$ & $16.9-19.9$ \\
\hline
\end{tabular}

${ }^{1}$ Three stalls were selected as observational objects (stalls 1, 2, and 3). The number of animals could change with management of the farm.

sion models were defined as the mean value during the observation periods. Referring to Hernández-Julio et al. (2014), rectal temperature and respiration rate data were converted to mean rectal temperature $\left(\mathbf{M R T},{ }^{\circ} \mathrm{C}\right)$ and mean respiration rate (MRR, bpm), respectively, to denote the heat stress of herds.

\section{Part I: Normal Rectal Temperature and the Regression Relationship Between Rectal Temperature and Respiration Rate}

Forty-five healthy, high-producing Holstein cows were randomly selected and identified by using tail spray paint. Rectal temperature and respiration rate were measured while cows were in headlocks in the time block of 1000-1100 h. The measurements were conducted from August 2 to September 30 (26 measurements on 26 test days at 1 - to 3 -d intervals). For cows included in the study, MY averaged $36.4 \mathrm{~kg} / \mathrm{d}$ (range from 24.1 to $49.4 \mathrm{~kg} / \mathrm{d}$ ); parity averaged 3 (range from 1 to 5 ); and DIM averaged 100 (range from 31 to 150 ) initially; $\mathrm{T}_{\mathrm{a}}$ averaged $22.0^{\circ} \mathrm{C}\left(9.5-30.8^{\circ} \mathrm{C}\right)$ and $\mathrm{RH}$ averaged $61.8 \%$ (37.9-82.2\%). The standard deviations (SD) of MY, parity, DIM, $\mathrm{T}_{\mathrm{a}}$, and $\mathrm{RH}$ were $5.8 \mathrm{~kg} / \mathrm{d}, 1.4,37.4 \mathrm{~d}$, $5.7^{\circ} \mathrm{C}$, and $13.7 \%$, respectively.

The relationship between MRT and MRR was described using simple linear regression. The normal MRT (the rectal temperature without being influenced by a hot environment) of herds was inferred from the correlation between MRT and $\mathrm{T}_{\mathrm{a}}$. The correlation between MRT and $T_{a}$ was described using a brokenline model with plateau $\left[\mathrm{MRT}=\mathrm{A}, \mathrm{T}_{\mathrm{a}} \leq \mathrm{B}\right.$; MRT $\left.=\mathrm{A}+\mathrm{C} \times\left(\mathrm{T}_{\mathrm{a}}-\mathrm{B}\right), \mathrm{T}_{\mathrm{a}}>\mathrm{B}\right]$. In this broken-line model, A (plateau) represents the normal MRT; B represents the upper critical temperature $\left(\mathbf{U C T},{ }^{\circ} \mathrm{C}\right.$ ) where rectal temperature started to rise; and $\mathrm{C}$ is the slope that reflects the response of MRT to $T_{a}$ above UCT. Furthermore, the normal MRR was inferred from the regression relationship between MRT and MRR. Additionally, correlations between MRT and MRR, as well as between MRR and $T_{a}$ were explored with simple linear or polynomial regression.

\section{Part II: Predicting Heat Stress Response Using Environment Predictors and MY in Different Time Blocks}

Three stalls (stalls 1, 2, and 3) were selected as observation objects. The information of these stalls is summarized in Table 1. The number of animals per stall fluctuated due to the management of the dairy farm: lactating cows unconfirmed to be pregnant could be moved to stall 1; pregnant cows could be moved to stall 2; cows in late gestation could be moved to stall 3; dry cows were moved away from stall 3 ; and cows that suffered from disease in these stalls were moved to a special shelter for clinical care.

The measurements were performed from July 22 to October 10 (39 test days of the whole period at 0- to 6 -d intervals) in herds different from those used in part I. The respiration rate data were collected during time blocks of $0630-0800,1230-1400$, and 1830-2000 h, the 90-min period before cows left their home stall for milking. A total of 253 data points were obtained during the whole observation period; MRR ranged from 35.3 to $105.9 \mathrm{bpm} ; \mathrm{T}_{\mathrm{a}}, \mathrm{RH}$, and WS ranged from 6.9 to $33.3^{\circ} \mathrm{C}$, from 31.8 to $99.7 \%$, and from 0 to $3.1 \mathrm{~m} / \mathrm{s}$, respectively. Binary dummy variables $(\mathrm{O} 1, \mathrm{O} 2)$ were created to represent the levels of observed time blocks, with binary code of $(0,0),(1,0)$ and $(0,1)$ standing for 0630-0800, 1230-1400, and 1230-1400 h, respectively. A set of numerical codes (0 to 82) was created to explore the effect of test day (TD). Note that in this part, the predictor MY represented the milk yield on the day before the TD because it might be too late to use MY of the TD to predict heat stress on the TD.

Regression analyses were performed and meaningful subsets retained. Residual standard errors (RSE) and adjusted $R^{2}$ were computed to evaluate predictive effects of regression models. We propose models with high adjusted $\mathrm{R}^{2}$, low RSE, and simple form. In addition, we evaluated the classification performance on ability to recognize the stress state (whether the heat stress response started or not) by computing the sensitivity, specificity, precision (positive predictive value), and accuracy (total consistency rate) using a confusion 
matrix $(2 \times 2$ cross-tabulation in diagnostic statistics $)$. To establish the confusion matrix, data points in part II were sorted into positive and negative cases based on the normal MRR (calculated from the regression relationship between MRT and MRR as well as the normal MRT in part I).

The predictive effects and classification performance of the proposed models were further compared with THI. The predictive effects of THI were evaluated by building regression models using THI, WS, time blocks, and MY. Note that in these models the assumption of THI threshold was eliminated. The classification performance of THI was evaluated using THI thresholds. Four THI thresholds were used for computing, including 72 (Armstrong, 1994), 68 (Collier et al., 2011), and 2 lower thresholds (64 and 60). The data points of part II would be recognized as heat stress if THI exceeded the threshold.

The equations of 6 THI used in cattle production (Bohmanova et al., 2007; Dikmen and Hansen, 2009) are listed as follows, with temperatures being calculated in degrees Celsius:

$$
\begin{aligned}
& \text { THI1 }=\left(1.8 \times \mathrm{T}_{\mathrm{a}}+32\right)-[(0.55-0.0055 \times \mathrm{RH}) \\
& \left.\times\left(1.8 \times \mathrm{T}_{\mathrm{a}}-26.8\right)\right](\mathrm{NRC}, 1971), \\
& \text { THI2 }=\mathrm{T}_{\mathrm{a}}+0.36 \times \mathrm{T}_{\mathrm{dp}}+41.2 \text { (Yousef, 1985) } \\
& \mathrm{THI} 3=\left(0.55 \times \mathrm{T}_{\mathrm{a}}+0.2 \times \mathrm{T}_{\mathrm{dp}}\right) \times 1.8 \\
& +49.5 \text { (NRC, 1971), } \\
& \text { THI } 4=\left(\mathrm{T}_{\mathrm{a}}+\mathrm{T}_{\mathrm{w}}\right) \times 0.72+40.6(\mathrm{NRC}, 1971), \\
& \text { THI5 }=0.8 \times \mathrm{T}_{\mathrm{a}}+(\mathrm{RH} / 100) \times\left(\mathrm{T}_{\mathrm{a}}-14.4\right) \\
& \text { + } 46.4 \text { (Mader et al., 2006), } \\
& \text { THI6 }=\left(0.35 \times \mathrm{T}_{\mathrm{a}}+0.65 \times \mathrm{T}_{\mathrm{w}}\right) \times 1.8 \\
& +32 \text { (Bianca, 1962), }
\end{aligned}
$$

where $T_{w}$ and $T_{d p}$ represent wet bulb and dewpoint temperatures $\left({ }^{\circ} \mathrm{C}\right)$, respectively.

We used one of the abovementioned THI equations for comparing the predictive and classification performance because there are high correlations between the different THI equations (Bohmanova et al., 2007; Dikmen and Hansen, 2009; Carabaño et al., 2016). We selected THI1 to represent the THI equations because it is often used in published papers involving dairy cattle.

To estimate the contribution of predictors to regression, the relative importance of predictors to $\mathrm{R}^{2}$ for the proposed models was calculated after regression analysis. Additionally, to demonstrate the temperaturehumidity effect for the proposed models, the relative importance of $\mathrm{T}_{\mathrm{a}}$ and $\mathrm{RH}$ for the proposed models was compared with that for the THI equations. Given that the THI equations have inconsistent humidity terms (e.g., $\mathrm{T}_{\mathrm{dp}}$ in THI2 and THI3; $\mathrm{T}_{\mathrm{w}}$ in THI4 and THI6), it is necessary to convert THI equations into a unified form to compare the temperature-humidity effect. Therefore, referring to Berman et al. (2016), we converted the 6 THI equations to unified expressions, combining both $\mathrm{T}_{\mathrm{a}}$ and $\mathrm{RH}$ effects via linear regression.

\section{Statistical Analysis}

All statistical procedures were performed using $\mathrm{R}$ software (version 3.4.4; https://www.R-project.org/). In part I, the broken-line model was fitted using the nls function; and simple linear and polynomial regression was performed using the $\mathrm{lm}$ function. In part II, considering the hierarchical structure of data, random effect was tested before regression analysis. The backward selection of random effects was executed using the step function of the lmerTest package through the likelihood ratio test (Kuznetsova et al., 2017). Models were compared in terms of Akaike information criterion (AIC) if using maximum likelihood estimation. Multiple regression was performed using the $\mathrm{lm}$ function in R. A 5\% level of significance was used throughout the regression process (both regression coefficients and full model). Goodness of fit was compared among subsets based on adjusted $\mathrm{R}^{2}$. We implemented regression diagnosis concerning collinearity, normality, linearity, and homoscedasticity to avoid misspecifications of fit. The collinearity between predictors was examined through the variance inflation factor (VIF), which was calculated using the vif function in $\mathrm{R}$. The assumption of normality was examined via the qqPlot function. Homoscedasticity was examined via residual plots and further confirmed via non-constant variance (NCV) test by using the ncvTest function in R. A model with funnel-shape residuals or an ncv.P-value $<0.05$ would be recognized to have a homoscedasticity problem. The vif, qqPlot, outlierTest, and ncvTest functions are available in the car package of $\mathrm{R}$.

In view of the potential interaction between predictors, before the regression process was started, we examined the correlation coefficients and partial correlation coefficients among variables. In addition, the interaction terms were added into the model to improve fit if they were significant.

Linearity of fit was examined by observing the distribution pattern of residuals. In this study, we utilized polynomials to accommodate nonlinear relationships 
between response and predictor variables. The orders of polynomials were selected by calculating crossvalidation mean squared errors $\left(\mathbf{M S E}_{\mathbf{c v}}\right)$ through the method of 10-fold cross-validation, which was implemented by using cv.glm function of the boot package in R. Receiver operator characteristic (ROC) curves were plotted with the pROC package of $\mathrm{R}$. The area under the curve (AUC) of 2 ROC curves were compared using roc.test function in $\mathrm{R}$.

The relative importance of predictors was compared using boot.relimp function included in relaimpo package (Grömping, 2006). Relative importance is defined as the proportional contribution that each predictor makes to $\mathrm{R}^{2}$ (Johnson and LeBreton, 2004). The relative importance of a predictor includes both linear and nonlinear terms (e.g., quadratic terms) for the same predictor. The sum of relative importance for all predictors is equal to 1 . The interaction terms were not input into models when calculating relative importance due to the collinearity problem between interaction terms and main effects. We set up a data set including $\mathrm{T}_{\mathrm{a}}$ and $\mathrm{RH}$, which ranged from 20 to $42^{\circ} \mathrm{C}$ in $1^{\circ} \mathrm{C}$ steps and from 10 to $90 \%$ in 1-percentage-unit steps, respectively. Values for $T_{d p}$ and $T_{w}$ were obtained from an online humidity calculator (https://www.rotronic.com), and THI was calculated from each temperature and humidity combination. Linear regression was performed to fit the response of THI to $\mathrm{T}_{\mathrm{a}}$ and $\mathrm{RH}$.

\section{RESULTS AND DISCUSSION}

\section{Part I: Normal Rectal Temperature and the Regression Relationship Between Rectal Temperature and Respiration Rate}

The relationships between MRT and $\mathrm{T}_{\mathrm{a}}$, MRT and MRR, and MRR and $\mathrm{T}_{\mathrm{a}}$ are shown in scatterplots (Figure 1). Regression analyses were performed and the residuals are shown in Figure 2. The relationship between MRT and $\mathrm{T}_{\mathrm{a}}$ (Figure 1a) described by the broken-line equation was obtained as follows:

$$
\begin{gathered}
\mathrm{MRT}=38.5, \mathrm{~T}_{\mathrm{a}} \leq 20.4 ; \\
\mathrm{MRT}=38.5+0.081 \times\left(\mathrm{T}_{\mathrm{a}}-20.4\right), \\
\mathrm{T}_{\mathrm{a}}>20.4\left(\mathrm{R}^{2}=0.817, P<0.001\right) .[\text { Eq. } 1-1]
\end{gathered}
$$

The 95\% CI of normal MRT, slope, and UCT in Eq. 1-1 were from 38.4 to 38.6 , from 0.06 to 0.10 , and from 18.2 to 22.6, respectively. From the residuals of Eq. 1-1 (Figure 2a), the broken-line model met the linear assumption approximately. The normal rectal temperature was estimated to be $38.5^{\circ} \mathrm{C}$, consistent with previous studies
(Dikmen and Hansen, 2009; Reuter et al., 2010; Lee et al., 2015). To make the estimate conservative, we set $38.6^{\circ} \mathrm{C}$ as the point at which rectal temperature started to rise because this value equaled the upper limit of 95\% CI of normal MRT. The UCT was determined to approximate 25 to $26^{\circ} \mathrm{C}$ by Berman et al. (1985) and Berman (2005), and $23^{\circ} \mathrm{C}$ by McArthur (1987). The UCT in this study was lower than in those reports. The calculation method of milk production of Berman et al. (1985) (daily FCM) and McArthur (1987) (lactation milk yield) are different from that in this study (daily milk yield). Thus, it is difficult to know whether the lower UCT of Eq. 1-1 was due to the effect of milk yield. Additionally, the physiological indicators for denoting heat stress response in Berman (2005) and McArthur (1987) are based on evaporative heat (from coat surface) and metabolic rate, respectively. We speculate that the differences of UCT among studies might be partly related to the inconsistent physiological indicators for denoting heat stress response among studies.

Given that some previous studies defined thresholds using the upper critical THI (UPTHI), we examined the relation between MRT and THI1 with the same broken-line equation form as Eq. 1-1:

$$
\begin{gathered}
\text { MRT }=38.5, \text { THI } 1 \leq 70 ; \\
\text { MRT }=38.5+0.035 \times(\text { THI } 1-70), \\
\text { THI } 1>70 ; \mathrm{R}^{2}=0.774 .
\end{gathered}
$$

The $95 \%$ CI of normal MRT of this equation was from 38.4 to 38.6 , which was identical to that of Eq. 1-1; the $95 \%$ CI of UPTHI was from 64 to 76 . The UPTHI is frequently regarded as 72 in earlier THI studies but in recent studies, UPTHI has been lowered to 68 (Collier et al., 2011). Our result could not be directly compared with that of Collier et al. (2011) because that study defined THI values as average, maximum, or minimum on a diurnal basis. The UPTHI of Dikmen and Hansen (2009) was higher than that of the current study (78 vs. 70), which could be related to the difference in MY between the 2 studies: $24 \mathrm{~kg} / \mathrm{d}$ for the former and 36 $\mathrm{kg} / \mathrm{d}$ for the latter.

The relationship between MRT and MRR is shown in Figure $1 \mathrm{~b}$ and the equation is as follows:

$$
\begin{gathered}
\mathrm{MRT}=0.021 \times \mathrm{MRR}+37.6 \\
\left(\mathrm{R}^{2}=0.925, P<0.001\right) .
\end{gathered}
$$

It can be seen from Figure 2b that Eq. 1-2 provided a good linear fit; the $95 \%$ CI of slope was from 0.019 to 0.024 . We can infer that each $0.1^{\circ} \mathrm{C}$ increase of MRT 
was accompanied by a 4.8-bpm increase in MRR, which is close to the $4.7 \mathrm{bpm}$ given by Gaughan et al. (2000). The relationship between MRT and MRR was strong and linear $(\mathrm{r}=0.963)$. The strong correlation between rectal temperature and respiration rate was also reported by Gaughan et al. (2000) and Gaughan and Mader
(2014). It can be inferred from both Eq. 1-1 and Eq. 1-2 that the response of MRR to the starting point of heat stress $\left(38.6^{\circ} \mathrm{C}\right.$ of MRT) is expected to be $48 \mathrm{bpm}$.

In Figure 1c, we can see a nonlinear trend between MRR and $T_{a}$. The expressions of both linear and quadratic polynomial functions, respectively, are as follows:

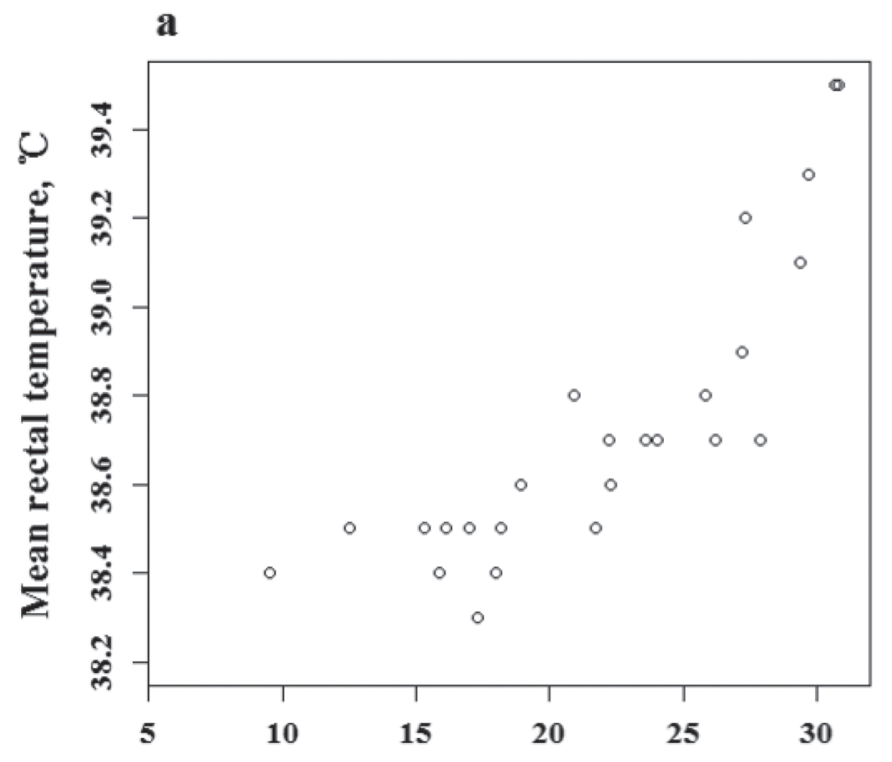

Ambient temperature, ${ }^{\circ} \mathrm{C}$

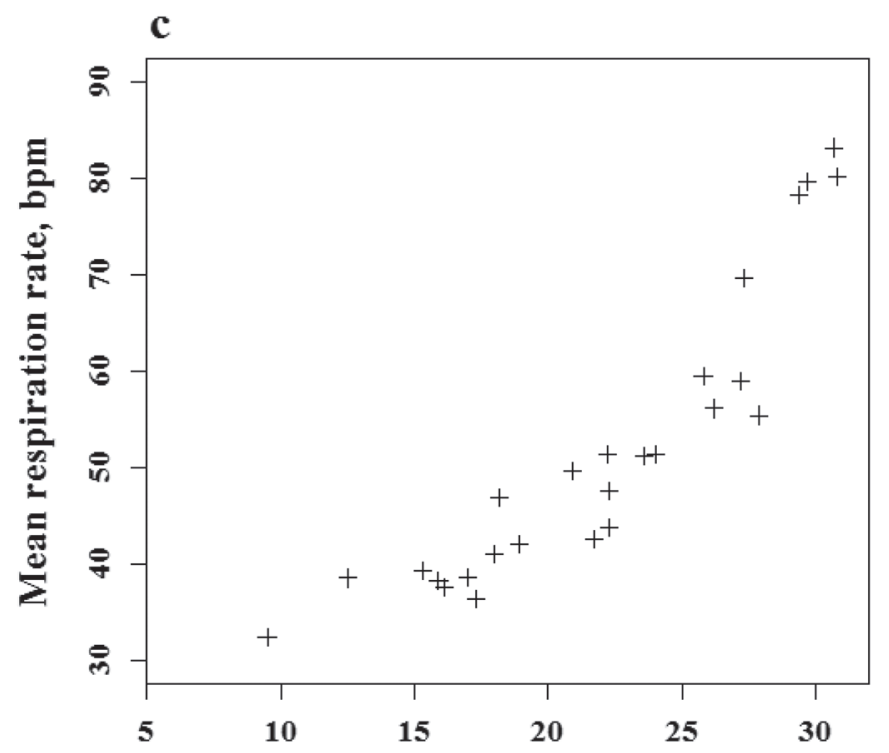

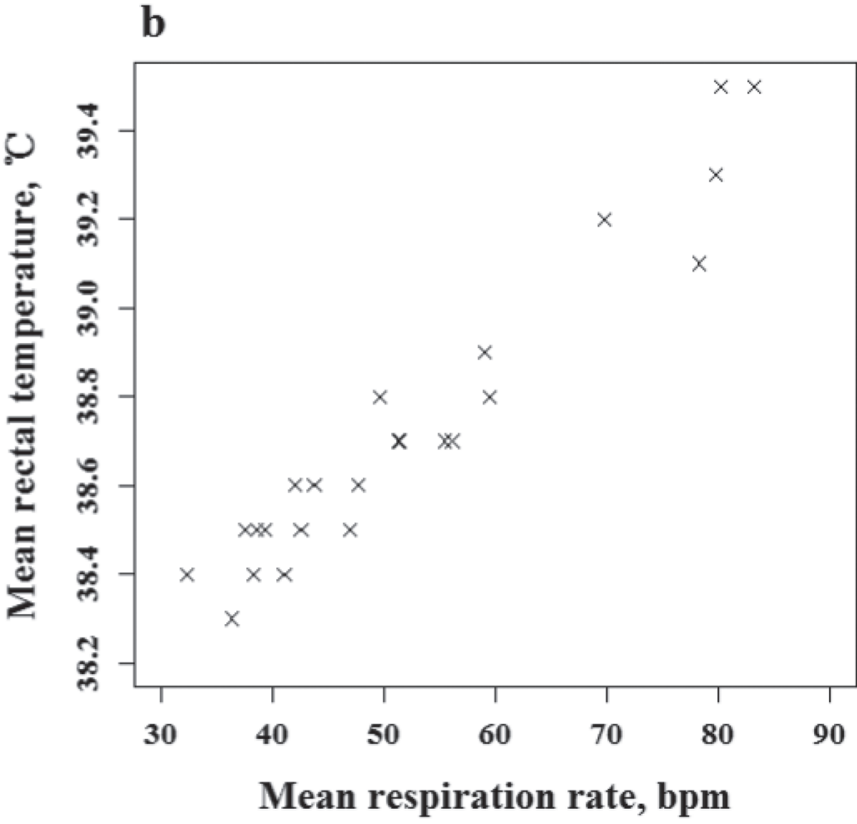

Ambient temperature, ${ }^{\circ} \mathrm{C}$

Figure 1. Scatterplots for mean rectal temperature (MRT) versus ambient temperature $\left(\mathrm{T}_{\mathrm{a}}\right.$; a), MRT versus mean respiration rate (MRR; b), and MRR versus $\mathrm{T}_{\mathrm{a}}(\mathrm{c})$ (study part I). Each point shows the MRT $\left({ }^{\circ} \mathrm{C}\right.$ ) or MRR (breaths/min, bpm) of the 45 observed cows in each measurement (a total of 26 measurements). The relationship between MRT and $\mathrm{T}_{\mathrm{a}}$ was expressed as Eq. 1-1; MRT and MRR followed a linear relationship, as shown in Eq. 1-2. The relationship between MRR and $\mathrm{T}_{\mathrm{a}}$ was examined using linear regression in Eq. 1-3 and quadratic regression in Eq. 1-4. 
$\mathrm{MRR}=0.5+2.34 \times \mathrm{T}_{\mathrm{a}}\left(\mathrm{R}^{2}=0.814, P<0.001\right)$

[Eq. 1-3]

$\mathrm{MRR}=57.6-3.42 \times \mathrm{T}_{\mathrm{a}}+0.13 \times \mathrm{T}_{\mathrm{a}}^{2}\left(\mathrm{R}^{2}=0.916\right.$, $P<0.001)$.

[Eq. 1-4]
As shown in Figure 2d and Figure 2c, Eq. 1-4 had a better linearization than Eq. 1-3 (the residuals of Eq. 1-3 had a U-shape whereas Eq. 1-4 did not). In addition, Eq. 1-4 showed a greater $\mathrm{R}^{2}$ than Eq. 1-3, suggesting a better fit of the quadratic term of $T_{a}$ than the linear term of $\mathrm{T}_{\mathrm{a}}$.
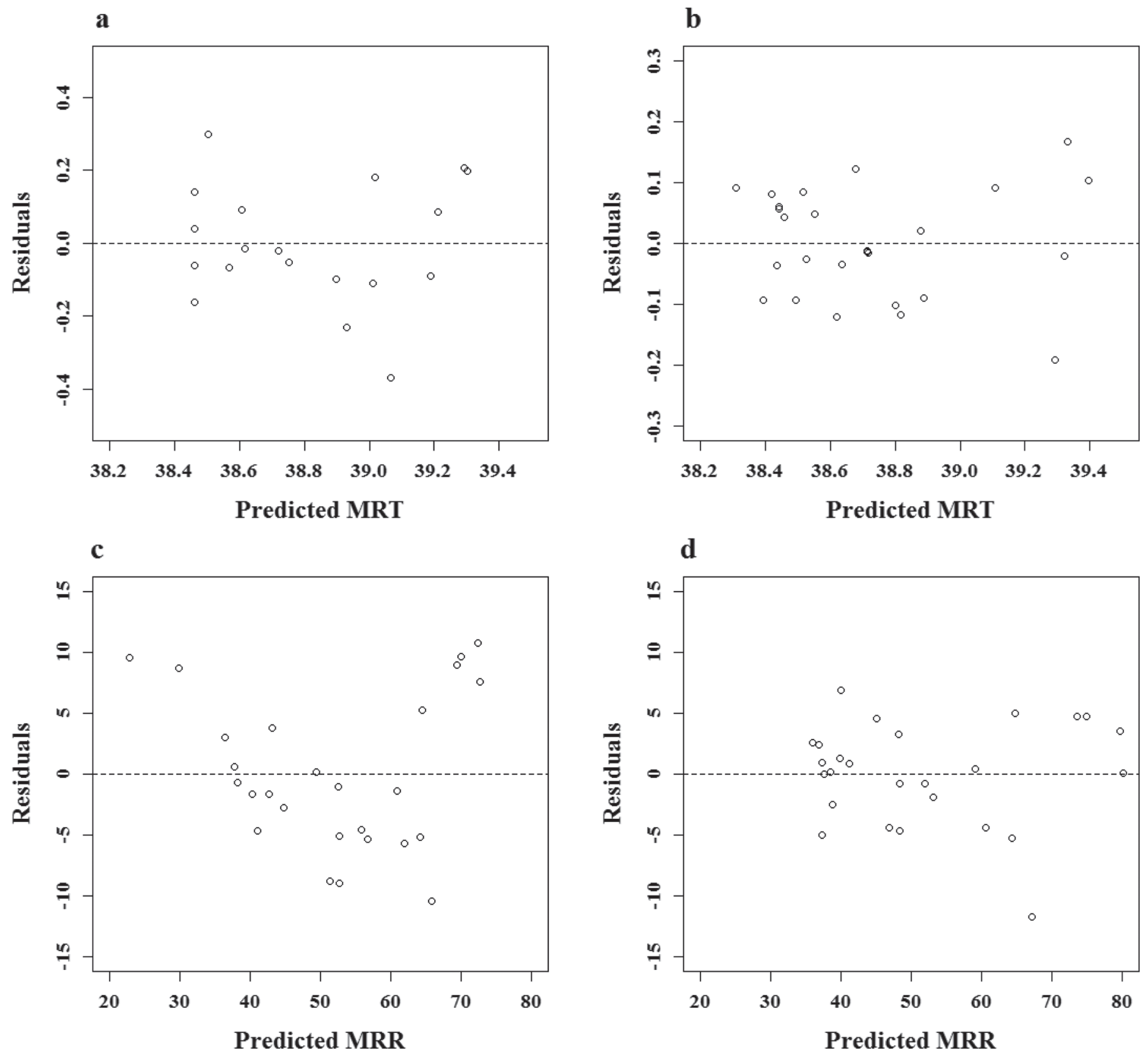

Figure 2. Residual plots for Eq. 1-1 (a), Eq. 1-2 (b), Eq. 1-3 (c), and Eq. 1-4 (d) (study part I). The points denote the residuals (distances between each measurements and the value predicted by the regression equation) for regression models: Eq. 1-1 [mean rectal temperature (MRT) vs. ambient temperature $\left(\mathrm{T}_{\mathrm{a}}\right)$ ], Eq. 1-2 [MRT vs. mean respiration rate (MRR)], Eq. 1-3 (MRR vs. $\mathrm{T}_{\mathrm{a}}$ ), and Eq. 1-4 (MRR vs. the quadratic term of $\mathrm{T}_{\mathrm{a}}$ ). Each point shows the MRT $\left({ }^{\circ} \mathrm{C}\right)$ or MRR (breaths/min) of the 45 observed cows in each measurement (a total of 26 measurements). 
Table 2. Summary of simple correlation coefficients between variables of interest (study part II) ${ }^{1}$

\begin{tabular}{lcccrr}
\hline Variable & TD & $\mathrm{T}_{\mathrm{a}}$ & $\mathrm{RH}$ & $\mathrm{WS}$ & \multicolumn{1}{c}{$\mathrm{MY}$} \\
\hline $\mathrm{MRR}$ & -0.73 & 0.77 & -0.01 & 0.32 & 0.23 \\
$\mathrm{TD}$ & & -0.80 & -0.10 & -0.59 & 0.08 \\
$\mathrm{~T}_{\mathrm{a}}$ & & & -0.24 & 0.55 & -0.06 \\
$\mathrm{RH}$ & & & & -0.20 & 0.04 \\
$\mathrm{WS}$ & & & & & -0.16 \\
\hline
\end{tabular}

${ }^{1} \mathrm{MRR}=$ mean respiration rate $($ breaths $/ \mathrm{min}) ; \mathrm{TD}=$ test day; $\mathrm{T}_{\mathrm{a}}=$ ambient temperature $\left({ }^{\circ} \mathrm{C}\right) ; \mathrm{RH}=$ relative humidity $(\%) ; \mathrm{WS}=$ wind speed $(\mathrm{m} / \mathrm{s}) ;$ and $\mathrm{MY}=$ milk yield of herd $(\mathrm{kg} / \mathrm{d})$.

\section{Part II: Predicting Heat Stress Response Using Environment Predictors and MY in Different Time Blocks}

In this part, predictive effects for models with different combinations of predictors $\left(\mathrm{T}_{\mathrm{a}}, \mathrm{RH}, \mathrm{WS}\right.$, time blocks, and MY) were compared. Before the regression process, we examined the relationship between variables of interest; after the regression process, predictive effects, classification performance, and relative importance of predictors for the proposed models were given.

\section{Examining the Relationship Between Variables Before Regression Analysis}

Before performing regression analysis, we examined collinearity between predictors. The correlation between predictors of interest is shown in Table 2. Ambient temperature was highly negatively correlated with TD $(\mathrm{r}=$ $-0.80)$ and there was significant collinearity between these 2 predictors $\left(\mathrm{VIF}^{0.5}>2\right)$. By virtue of this, TD was dropped from further analysis. Despite the moderate correlation between $\mathrm{T}_{\mathrm{a}}$ and WS $(\mathrm{r}=0.55)$, it was acceptable to input WS along with $\mathrm{T}_{\mathrm{a}}\left(\mathrm{VIF}^{0.5}<2\right)$.

The internal relationship between variables was further explored through partial coefficients (Table 3). As shown in Table 3, the partial coefficient between MRR and $\mathrm{RH}$ was 0.29 , which was much different than the simple correlation coefficient between them (0.01). According to the magnitude of partial coefficients between response variable and predictors, MY was more connected to the MRR response than either RH or WS.

The result of random effect test showed no significant random effect $(P>0.05)$ of $\mathrm{T}_{\mathrm{a}}, \mathrm{RH}, \mathrm{WS}$, and time blocks between stalls; there was a significant random effect of intercept $(P<0.01)$, suggesting that the overall response of MRR varied between stalls. We further compared the random intercept and fixed intercept using the maximum likelihood method. The result showed that the AIC of the fixed intercept model was smaller than that of random intercept model $(2,104.7$ vs. 2,112.2, $P<0.001$ ), suggesting a better fit of fixed intercept. Thus, the random intercept was replaced with the fixed intercept and the least squares method was used to estimate parameters.

Regression analysis was performed iteratively. Meaningful subsets were retained and are shown in Table 4 (Eq. 2-1 to 2-10); residuals of these subsets are shown in Figure 3. All of the subsets in Table 4 met the normality distribution hypothesis (data not shown), and all of the subsets in Table 4 were significant $(P<0.001)$.

\section{Response of MRR to Environment Predictors ( $T_{a}, R H$, and WS)}

Equations 2-1 to 2-5 showed the predictive effect of thermal environment predictors only. Equations 2-1 and 2-2 reflected the effect of the linear term of $\mathrm{T}_{\mathrm{a}}$; and Eq. 2-3, 2-4, and 2-5 reflected the effect of quadratic term of $T_{a}$. The residuals of both Eq. 2-1 and 2-2 (Figure $3 \mathrm{a}$ and $3 \mathrm{~b}$ ) showed a funnel shape, indicating heteroscedasticity, which was confirmed by NCV test (ncv.P $<0.05$ ). In contrast, residuals of Eq. 2-3, 2-4, and 2-5 (Figure 3c, 3d, and 3e) did not exhibit a funnel shape. The NCV test confirmed that Eq. 2-3, 2-4, and $2-5$ met the homogeneity assumption (ncv.P $>0.05$ ). The residuals of Eq. 2-2 showed a U shape, indicating a nonlinear trend. In comparison, Eq. 2-3, 2-4, and 2-5 approximately met a linearity assumption, implying that the quadratic term of $\mathrm{T}_{\mathrm{a}}$ could be conducive to avoid heteroscedasticity and nonlinearity problems. The $\mathrm{R}^{2}$ of Eq. 2-3, 2-4, and 2-5 were no less than that of Eq. 2-1 and 2-2. According to these results, the quadratic term of $T_{a}$ performed better than linear term of $\mathrm{T}_{\mathrm{a}}$ within these 5 equations.

From Figure 3a to 3e, we can see that the residuals of all 5 equations fell in a range of -20 to $20 \mathrm{bpm}$, corresponding to a range of -0.4 to $0.4^{\circ} \mathrm{C}$ of MRT (the relationship between MRT and MRR is inferred from Eq. 1-2).

Table 3. Summary of partial correlation coefficients between variables of interest (study part II) ${ }^{1}$

\begin{tabular}{lcrrr}
\hline Variable & $\mathrm{T}_{\mathrm{a}}$ & $\mathrm{RH}$ & $\mathrm{WS}$ & \multicolumn{1}{c}{$\mathrm{MY}$} \\
\hline $\mathrm{MRR}$ & 0.81 & 0.29 & -0.14 & 0.44 \\
$\mathrm{~T}_{\mathrm{a}}$ & & -0.33 & 0.42 & -0.34 \\
$\mathrm{RH}$ & & & -0.04 & -0.12 \\
$\mathrm{WS}$ & & & & -0.07 \\
\hline
\end{tabular}

${ }^{1} \mathrm{MRR}=$ mean respiration rate (breaths $\left./ \mathrm{min}\right) ; \mathrm{T}_{\mathrm{a}}=$ ambient temperature $\left({ }^{\circ} \mathrm{C}\right) ; \mathrm{RH}=$ relative humidity $(\%) ; \mathrm{WS}=$ wind speed $(\mathrm{m} / \mathrm{s})$; and $\mathrm{MY}=$ milk yield of herd $(\mathrm{kg} / \mathrm{d})$. 


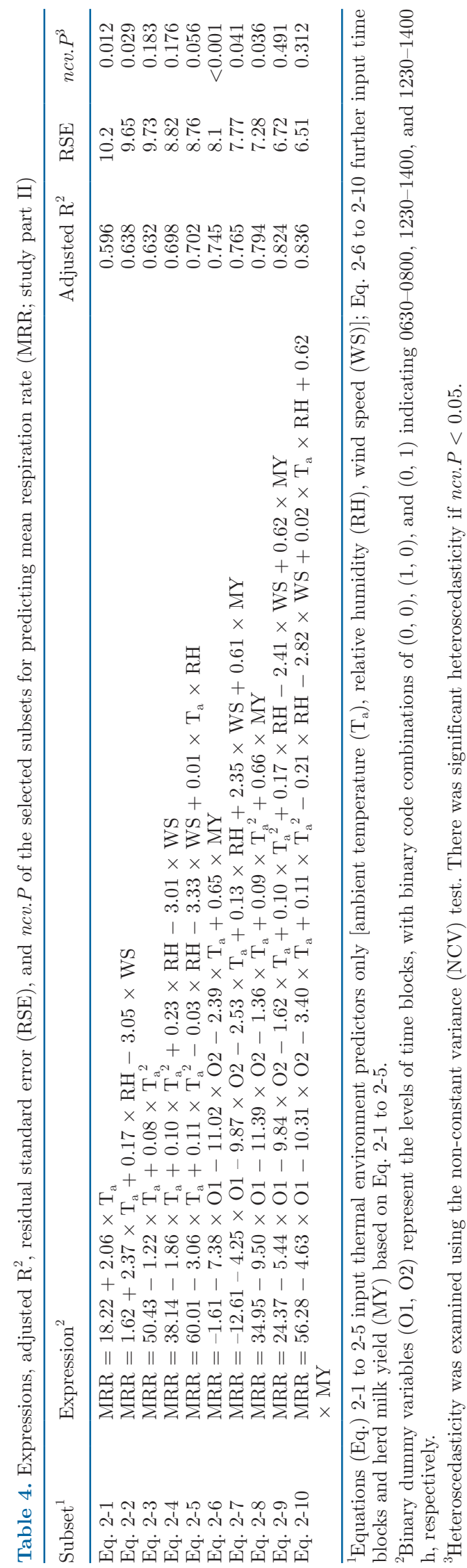

\section{Response of MRR to Environment Predictors and MY in Different Time Blocks}

Based on the combination patterns of Eq. 2-1 to 2-5, we further input time blocks and MY to each subset in sequence and acquired Eq. 2-6 to 2-10. Equations 2-6 and 2-7 reflected the effect of the linear term of $\mathrm{T}_{\mathrm{a}}$ (Figure 3f and 3g); and Eq. 2-8, 2-9, and 2-10 reflected the effect of the quadratic term of $\mathrm{T}_{\mathrm{a}}$ (Figure $3 \mathrm{~h}, 3 \mathrm{i}$, and $3 \mathrm{j}$ ). The $\mathrm{R}^{2}$ of Eq. 2-6 to 2-10 were larger than Eq. 2-1 to 2-5, respectively, with differences of at least 0.13. From Figure $3 \mathrm{f}$ to $3 \mathrm{j}$, it can be seen that most of the residuals of Eq. 2-6 to 2-10 fell in a range of -10 to 10 , corresponding to a range of -0.2 to $0.2^{\circ} \mathrm{C}$ of MRT, considerably lower than those of Eq. 2-1 to 2-5, indicating a pronounced reduction of error by adding time blocks and MY.

The residuals of Eq. 2-6 (Figure 3f) showed a clear $\mathrm{U}$ shape, indicating a nonlinear trend similar to that of Eq. 1-3. The coefficient of $T_{a}$ in Eq. 2-6 was similar to that of Eq. 1-3 (2.39 vs. 2.34), implying a similar response pattern of MRR to $\mathrm{T}_{\mathrm{a}}$ both in part I and part II.

The residuals of Eq. 2-6 and 2-7 had both funnel and U shapes, implying that Eq. 2-6 and 2-7 had problems with both heteroscedasticity $($ ncv.P $<0.05)$ and nonlinearity. In contrast, Eq. 2-8, 2-9, and 2-10 had no funnel or $\mathrm{U}$ shape, confirming that the quadratic term of $\mathrm{T}_{\mathrm{a}}$ corrected both heteroscedasticity and nonlinearity problems. The subsets including the quadratic term of $\mathrm{T}_{\mathrm{a}}$ (Eq. 2-8, 2-9, and 2-10) had a distinctly better fit than those including only the linear term of $\mathrm{T}_{\mathrm{a}}$ (Eq. 2-6 and 2-7). The quadratic term of $\mathrm{T}_{\mathrm{a}}$ was also used to correct the nonlinearity problem by Hernández-Julio et al. (2014).

The nonlinear relationship of heat stress response to $\mathrm{T}_{\mathrm{a}}$ was similar to that of previous THI studies (Bianca, 1962; Armstrong, 1994). This relationship could be associated with the nonlinear response of heat transfer from coat surface to environment (Bergman et al., 2011). Experimental results derived from Maia et al. (2005) suggested that both sensible and latent heat were highly correlated with $\mathrm{T}_{\mathrm{a}}$; the response of heat transfer from coat surface to environment followed a nonlinear relationship with $\mathrm{T}_{\mathrm{a}}$.

Moreover, the best order of $\mathrm{T}_{\mathrm{a}}$ was evaluated using a cross-validation method. The $\mathrm{MSE}_{\mathrm{cv}}$ of the first-order $\mathrm{T}_{\mathrm{a}}$ term was calculated from Eq. 2-7; the models combining higher-order $\mathrm{T}_{\mathrm{a}}$ terms were created by adding higher-order $\mathrm{T}_{\mathrm{a}}$ terms into Eq. 2-7. As detailed in Figure 4, compared with the linear term of $\mathrm{T}_{\mathrm{a}}(62.9)$, both the quadratic and cubic terms of $\mathrm{T}_{\mathrm{a}}$ (47.5 and 44.6, respectively) resulted in an obvious reduction of $\mathrm{MSE}_{\mathrm{cv}}$. There was no benefit in adding quartic or higher-order 

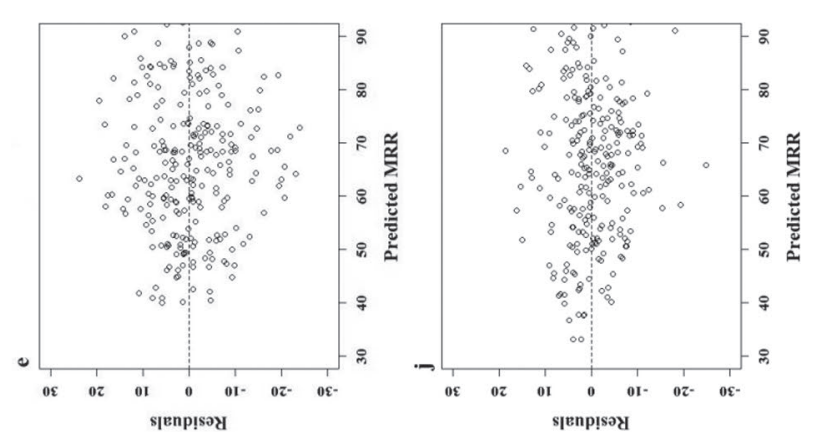

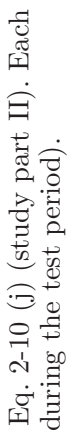
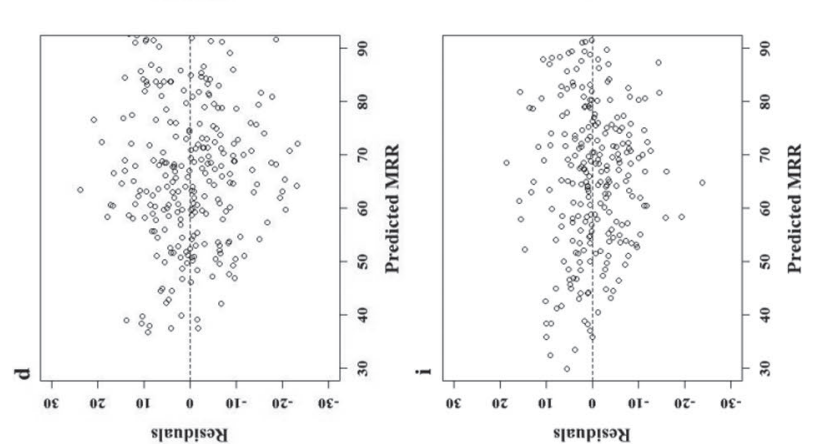

范水
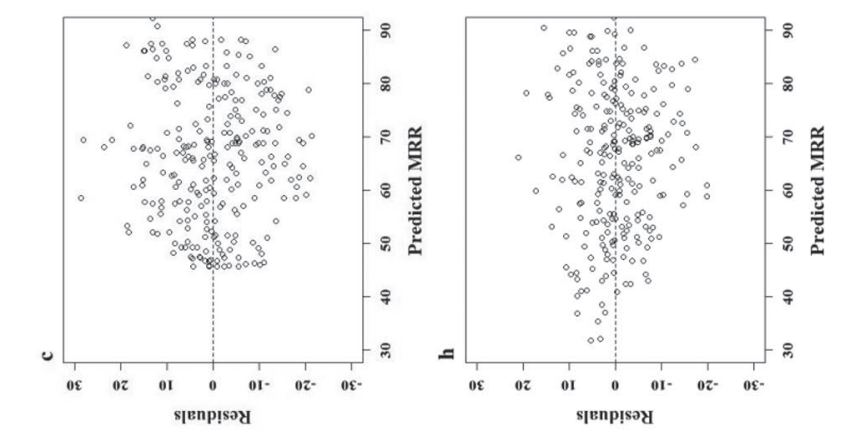

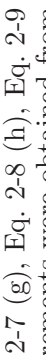

穴
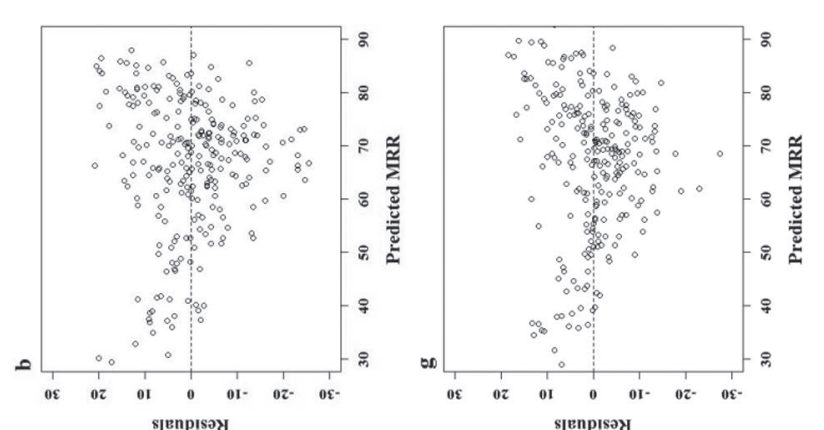

함ํㅛ

is

ํ. 켬
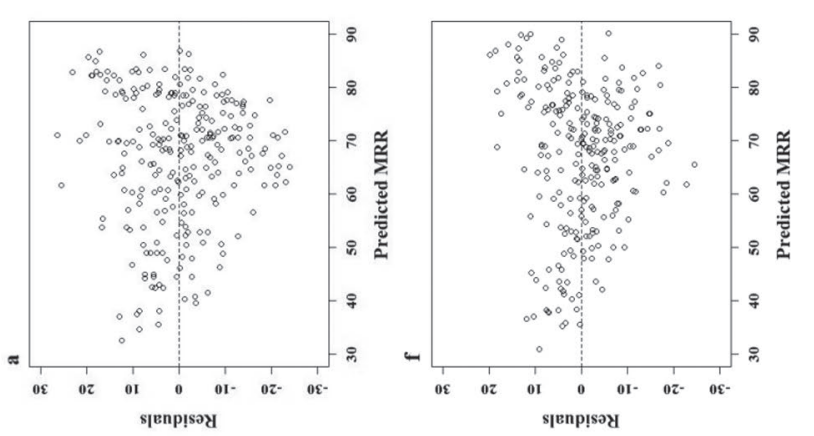

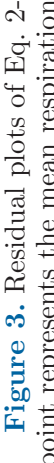


$\mathrm{T}_{\mathrm{a}}$ terms in the model. Two models combining the cubic term of $T_{a}$ were created as follows:

$$
\begin{gathered}
\mathrm{MRR}=-24.65-6.16 \times \mathrm{O} 1-9.88 \times \mathrm{O} 2-6.51 \\
\times \mathrm{T}_{\mathrm{a}}-0.32 \times \mathrm{T}_{\mathrm{a}}{ }^{2}+0.0066 \times \mathrm{T}_{\mathrm{a}}{ }^{3}+0.18 \times \mathrm{RH} \\
-1.64 \times \mathrm{WS}+0.64 \times \mathrm{MY}\left(\text { adjusted } \mathrm{R}^{2}=0.835\right. \\
\mathrm{RSE}=6.51, \text { ncv.P }=0.3, P<0.001)
\end{gathered}
$$

$$
\begin{gathered}
\mathrm{MRR}=5.34-5.34 \times \mathrm{O} 1-10.4 \times \mathrm{O} 2-5.42 \\
\times \mathrm{T}_{\mathrm{a}}-0.35 \times \mathrm{T}_{\mathrm{a}}^{2}-0.0073 \times \mathrm{T}_{\mathrm{a}}^{3}-0.24 \times \mathrm{RH} \\
\quad-2.01 \times \mathrm{WS}+0.02 \times \mathrm{T}_{\mathrm{a}} \times \mathrm{RH}+0.63 \\
\times \mathrm{MY} \text { (adjusted } \mathrm{R}^{2}=0.849, \mathrm{RSE}=6.23,
\end{gathered}
$$

$$
\text { ncv.P }=0.27, P<0.001) \text {. }
$$

Considering that there was little difference in $\mathrm{R}^{2}$ between Eq. 2-10 and Eq. 2-12 (0.836 vs. 0.849), we propose models with the quadratic term of $\mathrm{T}_{\mathrm{a}}$ (Eq. 2-9 or 2-10) for the purpose of simplicity. In addition, we merged the linear term of $T_{a}$, the quadratic term of $T_{a}$, and the interaction term between $\mathrm{T}_{\mathrm{a}}$ and $\mathrm{RH}$ in Eq. 2-10 into one term and obtained a simpler expression of Eq. 2-10:

$$
\begin{aligned}
& \mathrm{MRR}=56.28-4.63 \times \mathrm{O} 1-10.31 \times \mathrm{O} 2 \\
& +\left(-3.40+0.11 \times \mathrm{T}_{\mathrm{a}}+0.02 \times \mathrm{RH}\right) \times \mathrm{T}_{\mathrm{a}} \\
& -0.21 \times \mathrm{RH}-2.82 \times \mathrm{WS}+0.62 \times \mathrm{MY}
\end{aligned}
$$

From the slope of $\mathrm{T}_{\mathrm{a}}\left(-3.40+0.11 \times \mathrm{T}_{\mathrm{a}}+0.02 \times\right.$ $\mathrm{RH})$, it can be seen that the effect of $\mathrm{T}_{\mathrm{a}}$ on MRR would change with $\mathrm{T}_{\mathrm{a}}$ and $\mathrm{RH}$.

The coefficient of WS in Eq. 2-10 suggested a negative effect of WS on MRR. For each $1.7 \mathrm{~m} / \mathrm{s}$ increase in WS, the response of MRT could be expected to decrease by $0.1^{\circ} \mathrm{C}$ (the relationship between MRT and MRR is inferred from Eq. 1-2) after being adjusted by the other predictors. Note that there is no unified definition for determining WS in the literature because of the complex character of airflow, which is sensitive to housing structure and measuring method. For instance, Smith et al. (2006) and Shiao et al. (2011) acquired WS in similar tunnel ventilation structures using different measuring methods: WS derived from 3 different elevations in the former and from a fixed height in the latter. Some researchers place the measurement device in the center of the freestall but details are not always clear (Gaughan et al., 2002, 2008). Some researchers have obtained WS data from public weather stations

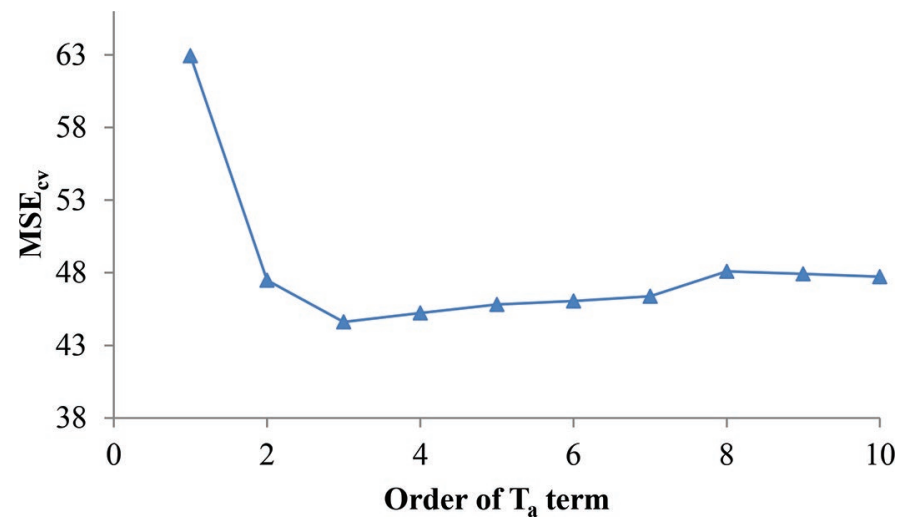

Figure 4. Cross-validation mean squared errors $\left(\mathrm{MSE}_{\mathrm{cv}}\right)$ of the models combined with different orders of ambient temperature $\left(\mathrm{T}_{\mathrm{a}}\right)$ terms (study part II). The $\mathrm{MSE}_{\mathrm{cv}}$ were estimated using method of 10 -fold cross-validation. The $\mathrm{MSE}_{\mathrm{cv}}$ of the first-order $\mathrm{T}_{\mathrm{a}}$ term was calculated from Eq. 2-7. Based on Eq. 2-7, the models with higher-order $\mathrm{T}_{\mathrm{a}}$ terms were created by adding higher-order $\mathrm{T}_{\mathrm{a}}$ terms in sequence.

(Brown-Brandl et al., 2005; Mader et al., 2010). Thus, the effect of WS in the current study could not be directly compared with that in previous studies.

\section{Effects of Time Blocks and Milk Yield in Prediction}

The value of dummy variables $\mathrm{O} 1$ and $\mathrm{O} 2$ in Eq. 2-6 to 2-10 showed that the overall response of MRR varied in different time blocks $(P<0.05)$; it was highest in 0630-0800 h, followed by 1230-1400 h, and then 1830$2000 \mathrm{~h}$. This order was inconsistent with the order of $T_{a}$ in the corresponding time blocks. The value of $T_{a}$ was highest in 1230-1400 h, followed by $1830-2000 \mathrm{~h}$, and then 0630-0800 h. Similarly, Atkins et al. (2018) found an inconsistent relationship between respiration rate and THI (THI has high correlation with $\mathrm{T}_{\mathrm{a}}$; Dikmen and Hansen, 2009) in some time blocks (e.g., 1800-0000 $\mathrm{h}$ and $0000-0400 \mathrm{~h}$ ). Further analysis by Atkins et al. (2018) indicated that body temperature had a consistent relationship with respiration rate: respiration rate increased and decreased, accompanied by a rise and fall in body temperature in different time blocks of a day. We infer that the inconsistent relationship between respiration rate and $T_{a}$ denotes the inconsistent relationship between body temperature and $\mathrm{T}_{\mathrm{a}}$ in the course of a day. We speculate that the fluctuation in MRR response could be associated with circadian body temperature rhythm. Kendall and Webster (2009) and Kendall et al. (2008) found that in spring and summer, vaginal temperature increased gradually from 0000 to $0600 \mathrm{~h}$ and peaked at $0600 \mathrm{~h}$ before the first milking; then it declined sharply from 0600 to 0800 $\mathrm{h}$ during the first milking (0630-0930 h); increased gradually after $0800 \mathrm{~h}$ and peaked at $1700 \mathrm{~h}$ during 
the second milking (1500-1700 h); after $1700 \mathrm{~h}$, vaginal temperature declined continuously and reached a nadir at $2100 \mathrm{~h}$. Their results suggested that the circadian body temperature could be closely associated with milking, displaying a high point before first milking, a middle point before second milking, and a low point after second milking. The order of heat stress response for the current study agrees with the circadian body temperature rhythm reported by Kendall and Webster (2009). However, previous reports on circadian body temperature rhythm showed different results (Igono and Johnson, 1990; Vickers et al., 2010; Allen et al., 2015). Further work is required to generalize the effects of time blocks in predicting heat stress. In this work, we are challenged by the problem that measurement of respiration rate was limited to certain fixed time blocks due to the restricted conditions. For instance, it was difficult to account for flank movements when cows were grazing or being milked. Further studies will be focused on collecting data in more time blocks with better sampling methods.

The positive coefficient of MY in Eq. 2-10 implies that the herds with higher MY would have higher respiration rates than herds with lower MY under the same environmental conditions (environment factors and time blocks). Combined with the inference of Eq. 1-2 (4.8 bpm of MRR denotes $0.1^{\circ} \mathrm{C}$ of MRT), within the range of MY (16.9 to $38.5 \mathrm{~kg} / \mathrm{d}$ ) and $\mathrm{T}_{\mathrm{a}}$ (6.9 to $33.3^{\circ} \mathrm{C}$ ), 2 herds that differ in MY by $7.7 \mathrm{~kg} / \mathrm{d}$ would be expected to have $0.1^{\circ} \mathrm{C}$ difference of body temperature when other predictors (environment factors and time blocks) are equal. In the current literature, it is rare to input MY as a predictor; therefore, it is difficult to know whether the estimated regulating effect of MY on heat stress in Eq. 2-10 is rational. Further studies should be conducted to confirm the relationship between MY and heat stress.

It is unclear whether the effects of time blocks and MY are moderated by $\mathrm{T}_{\mathrm{a}}$. Thus, the interactions between $\mathrm{T}_{\mathrm{a}}$ and time blocks and between $\mathrm{T}_{\mathrm{a}}$ and $\mathrm{MY}$ were input into Eq. 2-9. The former was significant $(P$ $<0.01)$ and the latter was not $(P>0.05)$. The model combining the interaction between $\mathrm{T}_{\mathrm{a}}$ and time blocks is as follows:

$$
\begin{gathered}
\mathrm{MRR}=29.63+19.4 \times \mathrm{O} 1-1.15 \times \mathrm{O} 1 \\
\times \mathrm{T}_{\mathrm{a}}+10.05 \times \mathrm{O} 2-0.96 \times \mathrm{T}_{\mathrm{a}} \times \mathrm{O} 2-2.87 \times \mathrm{T}_{\mathrm{a}} \\
+0.14 \times \mathrm{T}_{\mathrm{a}}{ }^{2}+0.17 \times \mathrm{RH}-2.66 \times \mathrm{WS}+0.63 \\
\times \mathrm{MY}\left(\text { adjusted } \mathrm{R}^{2}=0.839, \mathrm{RSE}=6.44,\right. \\
\quad \text { cvv.P }=0.27, P<0.001) . \quad[\text { Eq. } 2-13]
\end{gathered}
$$

The interaction terms $\left(\mathrm{O} 1 \times \mathrm{T}_{\mathrm{a}}\right.$ and $\left.\mathrm{O} 2 \times \mathrm{T}_{\mathrm{a}}\right)$ in Eq. 2-13 indicated that the difference of MRR between 0630 and $0800 \mathrm{~h}$ [binary code $(0,0)]$ and between 1230 and $1400 \mathrm{~h}$ [binary code $(1,0)$ ], as well as that between 0630 and $0800 \mathrm{~h}$ and 1830 and $2000 \mathrm{~h}$ [binary code $(0,1)$ ] would change if $\mathrm{T}_{\mathrm{a}}$ increased. From another perspective, these interaction terms suggested that the impact (slope) of $\mathrm{T}_{\mathrm{a}}$ on heat stress at different times of day would be different. In other words, the changing rate of MRR on $T_{a}$ would change over time in a course of day.

Considering that the interaction terms between $\mathrm{T}_{\mathrm{a}}$ and time blocks had only a slightly improvement on prediction but increased the complexity of model form and interpretation, we still consider Eq. 2-9 and Eq. 2-10 to be the best prediction equations.

To further interpret the relationship between $T_{a}$ and time blocks as well as that between $T_{a}$ and MY, we segmented the data set of part II based on the median of $\mathrm{T}_{\mathrm{a}}\left(24.5^{\circ} \mathrm{C}\right)$ and created 2 subsets of the same size. The 2 regression models for each subset are as follows:

$$
\begin{gathered}
\mathrm{MRR}=2.5-3.5 \times \mathrm{O} 1-8.0 \times \mathrm{O} 2-1.5 \\
\times \mathrm{T}_{\mathrm{a}}+0.13 \times \mathrm{RH}+0.65 \times \mathrm{MY}\left(6.9^{\circ} \mathrm{C}<\mathrm{T}_{\mathrm{a}}\right. \\
<24.5^{\circ} \mathrm{C}, \text { adjusted } \mathrm{R}^{2}=0.688, \mathrm{RSE}=6.15, \\
\text { ncv.P }=0.002, P<0.001), \quad[\text { Eq. 2-14] } \\
\mathrm{MRR}=181.4-9.0 \times \mathrm{O} 1-13.9 \times \mathrm{O} 2-14.1 \times \mathrm{T}_{\mathrm{a}} \\
+0.33 \times \mathrm{T}_{\mathrm{a}}{ }^{2}+0.31 \times \mathrm{RH}-2.5 \times \mathrm{WS}+0.66 \\
\times \mathrm{MY}\left(24.5^{\circ} \mathrm{C}<\mathrm{T}_{\mathrm{a}}<33.3^{\circ} \mathrm{C}, \text { adjusted } \mathrm{R}^{2}=0.777,\right. \\
\mathrm{RSE}=6.21, \text { ncv.P }=0.22, P<0.001) .
\end{gathered}
$$

[Eq. 2-15]

Equations 2-14 and Eq. 2-15 represented the regression relationships in the lower temperature range $\left(6.9^{\circ} \mathrm{C}<\right.$ $\left.\mathrm{T}_{\mathrm{a}}<24.5^{\circ} \mathrm{C}\right)$ and higher temperature range $\left(24.5^{\circ} \mathrm{C}<\right.$ $\mathrm{T}_{\mathrm{a}}<33.3^{\circ} \mathrm{C}$ ), respectively (these 2 equations were created only for interpreting the effects of MY and time blocks). The coefficients of MY in Eq. 2-10 (0.62), Eq. 2-14 (0.65), and Eq. 2-15 (0.66) were similar, suggesting less change in the MY effect in different temperature ranges. In contrast, from the coefficients of $\mathrm{O} 1$ and $\mathrm{O} 2$, the MRR in Eq. $2-15$ at $1230-1400 \mathrm{~h}$ and $1830-2000 \mathrm{~h}$ were 9.0 and $13.9 \mathrm{bpm}$ lower than that at $0630-0800$ $\mathrm{h}$, respectively; and the MRR in Eq. 2-14 at 1230-1400 $\mathrm{h}$ and 1830-2000 h were only 3.5 and $8.0 \mathrm{bpm}$ lower than that at $0630-0800 \mathrm{~h}$. These results support the inference on the effect of negative interaction between $\mathrm{T}_{\mathrm{a}}$ and time blocks in Eq. 2-13. That is, the negative interaction terms in Eq. 2-13 might make the absolute 
values of the coefficients of $\mathrm{O} 1$ and $\mathrm{O} 2$ larger when $\mathrm{T}_{\mathrm{a}}$ increases if combining the interaction terms into the main effect of $\mathrm{O} 1$ and $\mathrm{O} 2$. Thus, it implies that heat stress responses might fluctuate more among time blocks in a higher temperature range.

Additionally, the relative importance of time blocks and MY was calculated. Considering that the interaction term $\left(\mathrm{T}_{\mathrm{a}} \times \mathrm{RH}\right)$ in Eq. 2-10 can bring about a collinearity problem in calculating relative importance, Eq. 2-9 was used for calculation. The values of relative importance for $\mathrm{T}_{\mathrm{a}}, \mathrm{RH}, \mathrm{WS}$, time blocks, and MY were $76,3,5,8$, and $8 \%$, respectively in Eq. 2-9, implying that time blocks and MY should play an important role in prediction (time blocks and MY explained as much as $16 \%$ of $\mathrm{R}^{2}$ ).

\section{Classification Performance of Proposed Models, THI1, and UCT on Identifying Whether Heat Stress Was Triggered}

Based on the estimated MRR that heat stress was triggered (48 bpm, inferred from Eq. 1-1 and 1-2), the data points were sorted into positive and negative cases. There were 220 positive cases (MRR $>48 \mathrm{bpm}$, heat stress) and 33 negative cases (MRR $<48 \mathrm{bpm}$, no heat stress). We built confusion matrices for Eq. 2-10 (representing the proposed models), THI1 (representing THI equations), and UCT (inferred from Eq. 1-1). Three values of UCT were calculated, including upper CI $\left(22.6^{\circ} \mathrm{C}\right)$, mean $\left(20.4^{\circ} \mathrm{C}\right)$, and lower CI $\left(18.2^{\circ} \mathrm{C}\right)$. Data points with predictive MRR (calculated from Eq. 2-10) that exceeded $48 \mathrm{bpm}$ would be identified as heat stress. Data points with THI1 value exceeding the threshold or UCT would be recognized as heat stress.

The sensitivity, specificity, precision, and accuracy for Eq. 2-10, THI thresholds (72, 68, 64, and 60), and
UCT are listed in Table 5. As shown in Table 5, the sensitivity and accuracy of Eq. 2-10 were much higher than those of THI thresholds in the literature (72 and 68, respectively). Even if the threshold was lowered to 60, the sensitivity and accuracy for Eq. 2-10 were still higher than those of THI1. Similarly, the sensitivity and accuracy for Eq. 2-10 were higher than those for UCT. This implies that Eq. 2-10 performed better for recognizing heat stress. The improved performance for Eq. 2-10 might be because it combines more information (e.g., time blocks and MY) than THI or UCT.

The drawback of Eq. 2-10 is its lower specificity (51.5\%), which could bring about redundant cooling. If dairy farms prioritize to minimize stress-related production loss, it is more important to increase the sensitivity and accuracy of predictive models to minimize production loss, and Eq. 2-10 might be a feasible choice.

From Table 5, it can be seen that the lower THI threshold and UCT would have higher sensitivity and accuracy. The THI threshold of 60 and UCT of $18.2^{\circ} \mathrm{C}$ had similar sensitivity and accuracy to Eq. 2-10. Thus, we recommend Eq. 2-10, a lower THI threshold (e.g., 60 ), and a lower $\mathrm{UCT}$ (e.g., $18.2^{\circ} \mathrm{C}$ ) for identifying the stress state of herds.

\section{Difference in Classification Performance Between THI1 and $T_{a}$}

The difference in classification performance between THI1 and $\mathrm{T}_{\mathrm{a}}$ was compared using ROC curves (shown in Figure 5a and 5b, respectively). The AUC of the 2 ROC curves were 0.91 and 0.911 , respectively, suggesting that $\mathrm{T}_{\mathrm{a}}$ had a reliable classification performance in common with THI1. In addition, the 2 AUC did not differ statistically $(P=0.91)$. We infer that the classification performance of $\mathrm{T}_{\mathrm{a}}$ could be as good as that of

Table 5. The sensitivity, specificity, precision, and accuracy of both the proposed model, temperature-humidity index (THI1) and upper critical threshold (UCT) on recognizing stress state of herds (study part II)

\begin{tabular}{lcccc}
\hline Variable $^{1}$ & Sensitivity, $\%$ & Specificity, $\%$ & Precision, $\%$ & Accuracy, $\%$ \\
\hline Eq. 2-10 & 96.4 & 51.5 & 93.0 & 90.5 \\
THI $_{72}$ & 65.5 & 93.9 & 98.6 & 69.2 \\
THI $_{68}$ & 79.1 & 75.8 & 95.6 & 78.7 \\
THI $_{60}$ & 93.6 & 63.6 & 94.5 & 89.7 \\
HHI $_{64}$ & 88.2 & 72.7 & 95.6 & 86.2 \\
$\mathrm{UCT}_{22.6}$ & 69.1 & 94.4 & 97.4 & 81.5 \\
$\mathrm{UCT}_{20.4}$ & 80.9 & 84.0 & 95.7 & 85.2 \\
$\mathrm{UCT}_{18.2}$ & 87.7 & 75.0 & 95.5 & 85.8 \\
\hline
\end{tabular}

${ }^{1}$ The data points of part II were sorted to positive cases (heat stress, 220 cases) and negative cases (no heat stress, 33 cases) based on the inference of Eq. 1-1 and Eq. 1-2. The cases with estimated mean respiration rate (MRR) over 48 breaths/min (from the proposed model of Eq. 2-10) would be identified to be under heat stress. Four temperature-humidity index (THI) thresholds $(72,68,64$, and 60$)$ were used. The cases with THI exceeding THI threshold would be recognized to be under heat stress. $\mathrm{UCT}_{22.6}, \mathrm{UCT}_{20.4}$, and $\mathrm{UCT}_{18.2}$ represent the upper $95 \% \mathrm{CI}\left(22.6^{\circ} \mathrm{C}\right)$, mean $\left(20.4^{\circ} \mathrm{C}\right)$, and lower $95 \% \mathrm{CI}\left(18.2^{\circ} \mathrm{C}\right)$ of UCT in Eq. $1-1$, respectively. The cases with ambient temperature $\left(\mathrm{T}_{\mathrm{a}}\right)$ exceeding $\mathrm{UCT}$ would be recognized to be under heat stress. THI $1=(1.8$ $\left.\times \mathrm{T}_{\mathrm{a}}+32\right)-\left[(0.55-0.0055 \times \mathrm{RH}) \times\left(1.8 \times \mathrm{T}_{\mathrm{a}}-26.8\right)\right](\mathrm{NRC}, 1971)$. 

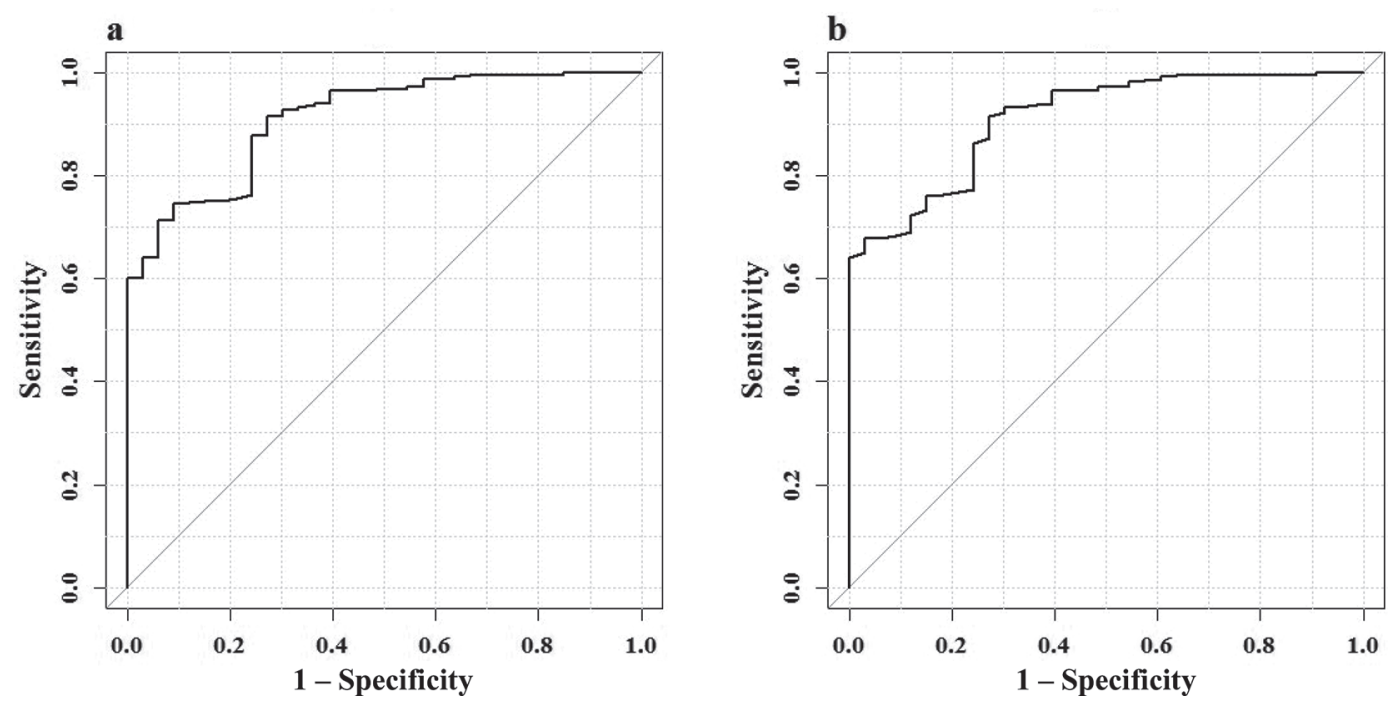

Figure 5. Receiver operator characteristic curves of temperature-humidity index (THI1; a) and ambient temperature ( $\mathrm{T}_{\mathrm{a}}$; b) on recognizing whether herds were under heat stress (study part II). THI1 $=\left(1.8 \times \mathrm{T}_{\mathrm{a}}+32\right)-\left[(0.55-0.0055 \times \mathrm{RH}) \times\left(1.8 \times \mathrm{T}_{\mathrm{a}}-26.8\right)\right](\mathrm{NRC}, 1971)$.

THI1. The similar performance between THI1 and $\mathrm{T}_{\mathrm{a}}$ could be associated with the high correlation $(\mathrm{r}=0.95)$ between them (Dikmen and Hansen, 2009).

\section{Predictive Effect of THI1}

We replaced $T_{a}$ and $R H$ with THI1 to examine the performance of THI1 on predicting MRR. The 4 regression models combining the THI1 effect are as follows:

$$
\begin{gathered}
\mathrm{MRR}=-34.9-1.42 \times \mathrm{THI} 1\left(\text { adjusted } \mathrm{R}^{2}=0.61\right. \\
\mathrm{RSE}=10.02, \text { ncv.P }=0.01, P<0.001)
\end{gathered}
$$

[Eq. 2-16]

$$
\begin{aligned}
& \mathrm{MRR}=-42.86-1.57 \times \mathrm{THI} 1-3.52 \times \mathrm{WS} \\
& \text { (adjusted } \mathrm{R}^{2}=0.626, \mathrm{RSE}=9.81, \\
& \text { ncv.P }=0.03, P<0.001) \text {, } \\
& \mathrm{MRR}=-58.87-3.76 \times \mathrm{O} 1-10.31 \times \mathrm{O} 2+1.57 \\
& \times \mathrm{THI}+0.65 \mathrm{MY} \text { (adjusted } \mathrm{R}^{2}=0.754, \\
& \mathrm{RSE}=7.96, n c v \cdot P=0.01, P<0.001),
\end{aligned}
$$

$$
\begin{gathered}
\mathrm{MRR}=-64.05-3.92 \times \mathrm{O} 1-10.48 \times \mathrm{O} 2 \\
+1.69 \times \mathrm{THI} 1-2.72 \times \mathrm{WS}+0.61 \\
\times \mathrm{MY} \text { (adjusted } \mathrm{R}^{2}=0.763, \mathrm{RSE}=7.81
\end{gathered}
$$

$$
n c v \cdot P=0.049, P<0.001) \text {. }
$$

[Eq. 2-19]
Equations 2-16 and 2-18 were created by substituting the $\mathrm{T}_{\mathrm{a}}$ term of Eq. 2-1 and 2-6 for THI1, respectively; Eq. 2-17 and 2-19 were built by replacing $\mathrm{T}_{\mathrm{a}}$ and $\mathrm{RH}$ of Eq. 2-2 and 2-7 with THI1, respectively. The residuals of Eq. 2-16, 2-17, 2-18, and 2-19 are given in Figure $6 \mathrm{a}, 6 \mathrm{~b}, 6 \mathrm{c}$, and 6d, respectively. Overall, the similar $\mathrm{U}$ shape and funnel shape of residuals of the 4 models (Eq. 2-16 to 2-19) demonstrated nonlinearity and heteroscedasticity $($ ncv. $P<0.05)$ problems in common. The $\mathrm{R}^{2}$ of Eq. 2-16 and 2-18 were slightly higher than that of Eq. 2-1 and 2-6, respectively, and the $\mathrm{R}^{2}$ of Eq. 2-17 and 2-19 were lower than Eq. 2-2 and 2-7, respectively. We infer that the predictive effect of THI1 was higher than that of $\mathrm{T}_{\mathrm{a}}$ but lower than the combination of $\mathrm{T}_{\mathrm{a}}$ and $\mathrm{RH}$.

The $\mathrm{R}^{2}$ of Eq. 2-10 was higher than that of Eq. 2-16 to 2-19 by at least 0.07. In addition, Eq. 2-10 did not have problems with nonlinearity and heteroscedasticity, implying that Eq. 2-10 has a better performance on controlling prediction bias and a better predictive effect than THI1.

\section{Difference in Temperature-Humidity Effect Between THI Equations and Proposed Models}

The THI 1 to THI6 equations were converted to unified expressions (the response of THI to $\mathrm{T}_{\mathrm{a}}$ and $\mathrm{RH}$ ) via a regression process (Table 6). Equations 3-1 to 3-6 represented THI1 to THI6, respectively (Table 6). From Table 6, Eq. 3-1 to 3-5 had similar coefficients of $\mathrm{T}_{\mathrm{a}}$ (1.30 to 1.33 ) and $\mathrm{RH}(0.13$ to 0.17$)$. The coefficients of $\mathrm{T}_{\mathrm{a}}(1.57)$ and $\mathrm{RH}(0.23)$ in Eq. 3-6 were higher than 
those in Eq. 3-1 to 3-5. The relative importance of RH in Eq. 3-6 (20.4\%) was also higher than that in Eq. 3-1 to $3-5$ (11.2 to $16.8 \%)$.

In Eq. 3-1 to 3-6, the ratios of relative importance between $\mathrm{RH}$ and $\mathrm{T}_{\mathrm{a}}$ were between 0.13 and 0.26 . In contrast, the ratio of relative importance between $\mathrm{RH}$ and $\mathrm{T}_{\mathrm{a}}$ in Eq. 2-9 was only 0.04. Thus, $\mathrm{RH}$ occupied only a small proportion of the temperature-humidity effect in Eq. 2-9, which is much lower than that in THI equations. The low proportion of $\mathrm{RH}$ in the temperature-humidity effect in Eq. 2-9 might be attributed to the weak linear dependency between $\mathrm{RH}$ and MRR. As demonstrated in Table 3, the partial correlation between RH and MRR (0.29) was much lower than that between $\mathrm{T}_{\mathrm{a}}$ and MRR $(0.81)$.

We propose 3 possible explanations for the aforementioned difference in temperature-humidity effect. The first involves the modeling strategies on coping with
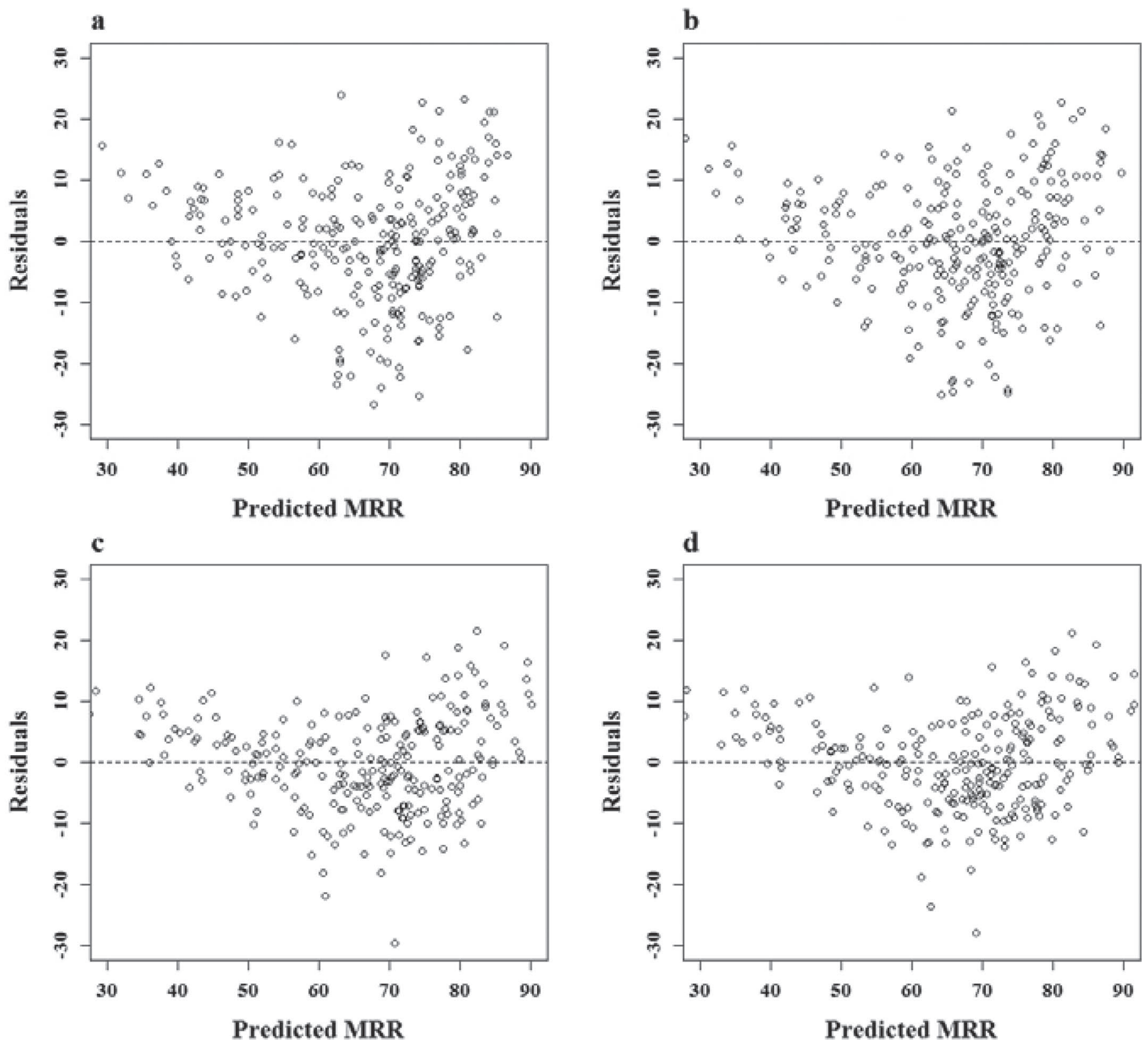

Figure 6. Residual plots of Eq. 2-16 (a), Eq. 2-17 (b), Eq. 2-18 (c), and Eq. 2-19 (d) (study part II). These models represent the predictive effect of temperature-humidity index (THI1) on heat stress response. THI1 $=\left(1.8 \times \mathrm{T}_{\mathrm{a}}+32\right)-\left[(0.55-0.0055 \times \mathrm{RH}) \times\left(1.8 \times \mathrm{T}_{\mathrm{a}}-26.8\right)\right]$, where $\mathrm{T}_{\mathrm{a}}=$ ambient temperature and $\mathrm{RH}=$ relative humidity (NRC, 1971). Each point represents the mean respiration rate (MRR, breaths/ min) for each measurement (a total of 253 measurements were obtained from 3 stalls during the test period). 
Table 6. The relative importance of ambient temperature $\left(\mathrm{T}_{\mathrm{a}}\right)$ and relative humidity $(\mathrm{RH})$ for temperature-humidity index (THI) equations (study part II)

\begin{tabular}{|c|c|c|c|c|}
\hline Equation ${ }^{1}$ & Expression $^{2}$ & $\mathrm{R}^{2}$ & $\operatorname{Imp}-\mathrm{T}_{\mathrm{a}}{ }^{3}{ }^{\%} \%$ & Imp-RH, ${ }^{3} \%$ \\
\hline Eq. 3-2 & $\mathrm{THI} 2=1.33 \times \mathrm{T}_{\mathrm{a}}+0.13 \times \mathrm{RH}+30.7$ & 0.994 & 88.8 & 11.2 \\
\hline Eq. 3-3 & $\mathrm{THI} 3=1.32 \times \mathrm{T}_{\mathrm{a}}+0.13 \times \mathrm{RH}+39.0$ & 0.993 & 88.6 & 11.4 \\
\hline Eq. 3-5 & $\mathrm{THI} 5=1.30 \times \mathrm{T}_{\mathrm{a}}+0.17 \times \mathrm{RH}+30.9$ & 0.974 & 83.2 & 16.8 \\
\hline Eq. 3-6 & THI $6=1.57 \times \mathrm{T}_{\mathrm{a}}+0.23 \times \mathrm{RH}+27.1$ & 0.992 & 79.6 & 20.4 \\
\hline
\end{tabular}

${ }^{1}$ Equations (Eq.) 3-1, 3-2, 3-3, 3-4, 3-5, and 3-6 represent THI1, THI2, THI3, THI4, THI5, and THI6, respectively.

${ }^{2}$ The equations for THI1 to THI6 are as follows: THI1 $=\left(1.8 \times \mathrm{T}_{\mathrm{a}}+32\right)-\left[(0.55-0.0055 \times \mathrm{RH}) \times\left(1.8 \times \mathrm{T}_{\mathrm{a}}-26.8\right)\right](\mathrm{NRC}, 1971) ; \mathrm{THI} 2=$ $\mathrm{T}_{\mathrm{a}}+0.36 \times \mathrm{T}_{\mathrm{dp}}+41.2$ (Yousef, 1985); THI3 $=\left(0.55 \times \mathrm{T}_{\mathrm{a}}+0.2 \times \mathrm{T}_{\mathrm{dp}}\right) \times 1.8+49.5(\mathrm{NRC}, 1971) ; \mathrm{THI}_{4}=\left(\mathrm{T}_{\mathrm{a}}+\mathrm{T}_{\mathrm{w}}\right) \times 0.72+40.6(\mathrm{NRC}$, 1971); THI5 $=0.8 \times \mathrm{T}_{\mathrm{a}}+(\mathrm{RH} / 100) \times\left(\mathrm{T}_{\mathrm{a}}-14.4\right)+46.4$ (Mader et al., 2006); THI6 $=\left(0.35 \times \mathrm{T}_{\mathrm{a}}+0.65 \times \mathrm{T}_{\mathrm{w}}\right) \times 1.8+32($ Bianca, 1962$) ;$ $\mathrm{T}_{\mathrm{w}}$ and $\mathrm{T}_{\mathrm{dp}}$ represent wet bulb and dewpoint temperatures $\left({ }^{\circ} \mathrm{C}\right)$, respectively. All 6 of the THI equations were converted to the same combination (the response of THI to $\mathrm{T}_{\mathrm{a}}$ and $\mathrm{RH}$ ) through linear regression for the convenience of calculating relative importance.

${ }^{3} \mathrm{Imp}-\mathrm{T}_{\mathrm{a}}$ and Imp-RH represent the relative importance of $\mathrm{T}_{\mathrm{a}}$ and $\mathrm{RH}$, respectively. The sum of Imp- $\mathrm{T}_{\mathrm{a}}$ and Imp- $\mathrm{RH}$ is equal to $100 \%$. The relative importance is defined as the proportionate contribution that each predictor makes to $\mathrm{R}^{2}$.

the nonlinear relationship between $\mathrm{T}_{\mathrm{a}}$ and heat stress response: THI uses a curve fitting method by adjusting the coefficients of both temperature and humidity term manually rather than by linear regression. This strategy assumed that the nonlinear curve of body temperature to the temperature term could be linearized by the humidity term. For instance, Bianca (1962) set 0.65 to $\mathrm{T}_{\mathrm{a}}$ and 0.35 to $\mathrm{T}_{\mathrm{w}}$ to match the curve of body temperature to $\mathrm{T}_{\mathrm{a}}$. A similar modeling strategy was seen in THI studies that applied the concept of effective temperature by constructing a set of reaction curves (isograms) with a 2-dimensional coordinate system, with the abscissa and ordinate representing $\mathrm{T}_{\mathrm{a}}$ and RH, respectively (NRC, 1971; Armstrong, 1994; Havenith and Fiala, 2015). With those strategies, the nonlinearity response of body temperature on $T_{a}$ would be linearized by the humidity term. However, according to regression analyses of this study, $\mathrm{RH}$ did not alter the nonlinearity between $\mathrm{T}_{\mathrm{a}}$ and MRR (after inputting $\mathrm{RH}$ into Eq. 2-7, the $\mathrm{U}$ shape of the residual did not change), and the nonlinearity term of $\mathrm{T}_{\mathrm{a}}$ (e.g., the quadratic term of $T_{a}$ ) satisfied the need to correct nonlinearity. If using the humidity term to correct nonlinearity (the modeling strategies of THI) between $\mathrm{T}_{\mathrm{a}}$ and the heat stress response, the humidity term would account for more variance. In other words, the variance explained by nonlinear terms of $\mathrm{T}_{\mathrm{a}}$ could be explained by $\mathrm{RH}$ instead, which would increase the relative importance of RH.

The second possible explanation is the difference in temperature range. The ceiling limit of $\mathrm{T}_{\mathrm{a}}$ in part II was $33.3^{\circ} \mathrm{C}$, which is lower than that of THI (much higher than $42^{\circ} \mathrm{C}$; Armstrong, 1994). At different $\mathrm{T}_{\mathrm{a}}$, the pattern of heat exchange might be different. For instance, sensible heat exchange on the coat surface will change with $\mathrm{T}_{\mathrm{a}}$. Accompanied by an increase in $\mathrm{T}_{\mathrm{a}}$, the temperature difference between coat surface and environment will reduce and sensible heat exchange will decrease (Maia et al., 2005; Collier and Gebremedhin, 2015). Under $\mathrm{T}_{\mathrm{a}}$ of $30^{\circ} \mathrm{C}$, the coat surface temperature was $5.3^{\circ} \mathrm{C}$ higher than $\mathrm{T}_{\mathrm{a}}$; in contrast, under $35^{\circ} \mathrm{C}$, the coat surface temperature was $0.9^{\circ} \mathrm{C}$ lower than $\mathrm{T}_{\mathrm{a}}$ and cows were unable to dissipate heat through sensible heat exchange (Jiang et al., 2005). Thus, latent heat exchange from both coat surface and respiratory tract to the environment is the main method of heat dissipation for cows under high $\mathrm{T}_{\mathrm{a}}$ (Monteith and Unsworth, 2013). The effect of $\mathrm{RH}$ on heat stress might increase with the increase in $\mathrm{T}_{\mathrm{a}}$ because of the negative correlation between RH and latent heat exchange. The equations Eq. 2-14 and 2-15 also indicated a relationship between temperature range and $\mathrm{RH}$ effect. The coefficient of $\mathrm{RH}$ in Eq. 2-15 (0.31) was more than twice that in Eq. 2-14, implying that the effect of $\mathrm{RH}$ on heat stress in a higher temperature range $\left(24.5^{\circ} \mathrm{C}<\mathrm{T}_{\mathrm{a}}<33.3^{\circ} \mathrm{C}\right.$, Eq. 2-15) would be higher than that in a lower temperature range $\left(6.9^{\circ} \mathrm{C}<\mathrm{T}_{\mathrm{a}}<24.5^{\circ} \mathrm{C}\right.$, Eq. 2-14). It is logical that there would be a greater effect of $\mathrm{RH}$ on heat stress when $\mathrm{T}_{\mathrm{a}}$ exceeds $33.3^{\circ} \mathrm{C}$. Thus, the higher proportion of $\mathrm{RH}$ in the temperature-humidity effect for THI might be due to the higher ceiling limit of $\mathrm{T}_{\mathrm{a}}$ in THI.

The third possible explanation involves the effect of the quadratic term of $\mathrm{T}_{\mathrm{a}}$. As discussed above, the effect of RH in Eq. 2-15 was greater than that in Eq. 2-14. In contrast, the ratio of relative importance of $\mathrm{RH}$ to $\mathrm{T}_{\mathrm{a}}$ in Eq. 2-15 (0.04) was much lower than that in Eq. 2-14 (0.22). That is, the proportion of $\mathrm{RH}$ in temperaturehumidity effect within the higher temperature range was still lower than that within the lower temperature range even if $\mathrm{RH}$ had a greater impact on heat stress within the higher temperature range. The major difference between Eq. 2-14 and Eq. 2-15 is the effect of $\mathrm{T}_{\mathrm{a}}$. The latter has the quadratic term of $\mathrm{T}_{\mathrm{a}}$ whereas the former does not (only has linear term of $\mathrm{T}_{\mathrm{a}}$ ). The 
quadratic term of $\mathrm{T}_{\mathrm{a}}$ might bring about a greater effect on variance compared with the linear term of $T_{a}$ because of the higher rate of increment for the quadratic term compared with the linear term. That is, the quadratic term of $\mathrm{T}_{\mathrm{a}}$ could result in a larger proportion of temperature-humidity effect for $\mathrm{T}_{\mathrm{a}}$ in Eq. 2-15. In this sense, the lower proportion of temperature-humidity effect for RH in Eq. 2-9 (compared with THI equations) could be associated with the effect of quadratic term of $\mathrm{T}_{\mathrm{a}}$.

To summarize, the proposed models (Eq. 2-9 and Eq. 2-10) differ from THI1 in many aspects, including predictive effect, classification performance, and temperature-humidity effect. As discussed above, the temperature range is closely associated with the effectiveness of the proposed models. Two additional aspects might be worth noting. One is that the predictors in the regression analysis were assumed to be nonrandom variables; the other is that the coefficients of predictors would change if the defined range of temperature changes. Therefore, we do not suggest extrapolating the proposed models to an environment with $\mathrm{T}_{\mathrm{a}}$ exceeding $33.3^{\circ} \mathrm{C}$. Additionally, the 3 time blocks in the proposed models represented time periods in the morning (0630-0800 h), afternoon (1230-1400 h), and night (1830-2000 h), respectively, and all 3 time blocks were before milking. Considering that morning, afternoon, and nighttime milking times for dairy farms would not be exactly the same, we suggest that the time blocks in the proposed models can be generalized to time periods of 90 min before milking in the morning, afternoon, and night in practice. Further research might explore how to generalize the effects of time blocks on predicting heat stress.

\section{CONCLUSIONS}

Altogether, our results suggest that the information of milk yield and time blocks is important for predicting respiration rate of dairy herds under a hot climate. Under the same environmental conditions, the herd with higher milk yield would have higher respiration rate than that with lower milk yield. Additionally, the response of respiration rate is different among time blocks. Furthermore, the quadratic term of ambient temperature is beneficial to reduce the prediction error. The predictive models that combine milk yield, time blocks, and the quadratic term of ambient temperature have better performance compared with THI equations.

\section{ACKNOWLEDGMENTS}

This study was financed by National Key R\&D Program of China (2016YFD0500507, 2017YFD0502003), the Beijing Dairy Industry Innovation Team Project (BAIC06-2019), and the Agricultural Science and Technology Innovation Program (ASTIP-IAS07). We are grateful to Yutao Yang and Tingchen Yang, of Beijing Zhongdi dairy farm, for their help with data collection, and to Huaigu Yang, Hui Wang, Congcong Li, Chuang Zhang, and Guangju Wang (all affiliated with the Chinese Academy of Agricultural Sciences, Beijing) for their suggestions about this work. The authors declare that there are no conflicts of interest.

\section{REFERENCES}

Allen, J. D., L. W. Hall, R. J. Collier, and J. F. Smith. 2015. Effect of core body temperature, time of day, and climate conditions on behavioral patterns of lactating dairy cows experiencing mild to moderate heat stress. J. Dairy Sci. 98:118-127. https://doi.org/10 .3168/jds.2013-7704.

Armstrong, D. V. 1994. Heat stress interaction with shade and cooling. J. Dairy Sci. 77:2044-2050. https://doi.org/10.3168/jds.S0022 -0302(94)77149-6.

Atkins, I. K., N. B. Cook, M. R. Mondaca, and C. Y. Choi. 2018. Continuous respiration rate measurement of heat-stressed dairy cows and relation to environment, body temperature, and lying time. Trans. ASABE 61:1475-1485. https://doi.org/10.13031/ trans. 12451.

Barash, H., N. Silanikove, A. Shamay, and E. Ezra. 2001. Interrelationships among ambient temperature, day length, and milk yield in dairy cows under a Mediterranean climate. J. Dairy Sci. 84:23142320. https://doi.org/10.3168/jds.S0022-0302(01)74679-6.

Bergman, T. L., F. P. Incropera, D. P. DeWitt, and A. S. Lavine. 2011. Fundamentals of Heat and Mass Transfer. 7th ed. John Wiley \& Sons Inc., Hoboken, NJ.

Berman, A. 2003. Effects of body surface area estimates on predicted energy requirements and heat stress. J. Dairy Sci. 86:3605-3610. https://doi.org/10.3168/jds.S0022-0302(03)73966-6.

Berman, A. 2005. Estimates of heat stress relief needs for Holstein dairy cows. J. Anim. Sci. 83:1377-1384. https://doi.org/10.2527/ 2005.8361377x.

Berman, A., Y. Folman, M. Kaim, M. Mamen, Z. Herz, D. Wolfenson, A. Arieli, and Y. Graber. 1985. Upper critical temperatures and forced ventilation effects for high-yielding dairy cows in a subtropical climate. J. Dairy Sci. 68:1488-1495. https://doi.org/10.3168/ jds.S0022-0302(85)80987-5.

Berman, A., T. Horovitz, M. Kaim, and H. Gacitua. 2016. A comparison of THI indices leads to a sensible heat-based heat stress index for shaded cattle that aligns temperature and humidity stress. Int. J. Biometeorol. 60:1453-1462. https://doi.org/10.1007/s00484-016 $-1136-9$.

Bianca, W. 1962. Relative importance of dry-and wet-bulb temperatures in causing heat stress in cattle. Nature 195:251-252. https:/ /doi.org/10.1038/195251a0.

Bohmanova, J., I. Misztal, and J. B. Cole. 2007. Temperature-humidity indices as indicators of milk production losses due to heat stress. J. Dairy Sci. 90:1947-1956. https://doi.org/10.3168/jds.2006-513.

Brown-Brandl, T. M., R. A. Eigenberg, J. A. Nienaber, and G. L. Hahn. 2005a. Dynamic response indicators of heat stress in shaded and non-shaded feedlot cattle, Part 1: Analyses of indicators. Biosyst. Eng. 90:451-462. https://doi.org/10.1016/j.biosystemseng .2004.12.006.

Brown-Brandl, T. M., D. D. Jones, and W. E. Woldt. 2005b. Evaluating modelling techniques for cattle heat stress prediction. Biosyst. Eng. 91:513-524. https://doi.org/10.1016/j.biosystemseng.2005.04 .003 .

Carabaño, M. J., K. Bachagha, M. Ramón, and C. Díaz. 2014. Modeling heat stress effect on Holstein cows under hot and dry condi- 
tions: Selection tools. J. Dairy Sci. 97:7889-7904. https://doi.org/ $10.3168 /$ jds.2014-8023.

Carabaño, M. J., B. Logar, J. Bormann, J. Minet, M. L. Vanrobays, C. Díaz, B. Tychon, N. Gengler, and H. Hammami. 2016. Modeling heat stress under different environmental conditions. J. Dairy Sci. 99:3798-3814. https://doi.org/10.3168/jds.2015-10212.

Collier, R. J., R. M. Eley, A. K. Sharma, R. M. Pereira, and D. E. Buffington. 1981. Shade management in subtropical environment for milk yield and composition in Holstein and Jersey cows. J. Dairy Sci. 64:844-849. https://doi.org/10.3168/jds.S0022-0302(81)82656 -2 .

Collier, R. J., and K. G. Gebremedhin. 2015. Thermal biology of domestic animals. Annu. Rev. Anim. Biosci. 3:513-532. https://doi .org/10.1146/annurev-animal-022114-110659.

Collier, R. J., B. J. Renquist, and Y. Xiao. 2017. A 100-Year Review: Stress physiology including heat stress. J. Dairy Sci. 100:1036710380. https://doi.org/10.3168/jds.2017-13676.

Collier, R. J., and R. B. Zimbelman. 2007. Heat stress effects on cattle: What we know and what we don't know. Pages 76-83 in Proc. 22nd Annual Southwest Nutrition \& Management Conference, Tempe, AZ. https://cals.arizona.edu/extension/dairy/az_nm_newsletter/ 2007/june.pdf.

Collier, R. J., R. B. Zimbelman, R. P. Rhoads, M. L. Rhoads, and L. H. Baumgard. 2011. A re-evaluation of the impact of temperature humidity index (THI) and black globe humidity index (BGHI) on milk production in high producing dairy cows. Pages 113-125 in Proc. Western Dairy Management Conf., Reno, NV. https://pdfs.semanticscholar.org/4c59/ e3f5eee2c64461d2b425814da9b4514616e6.pdf?_ga=2.209434779 .869193502.1584634077-240108594.1584634077.

Da Silva, R. G., A. S. C. Maia, and L. L. de Macedo Costa. 2015. Index of thermal stress for cows (ITSC) under high solar radiation in tropical environments. Int. J. Biometeorol. 59:551-559. https:// doi.org/10.1007/s00484-014-0868-7.

de Andrade Ferrazza, R., H. D. Mogollón Garcia, V. H. Vallejo Aristizábal, C. de Souza Nogueira, C. J. Veríssimo, J. R. Sartori, R. Sartori, and J. C. Pinheiro Ferreira. 2017. Thermoregulatory responses of Holstein cows exposed to experimentally induced heat stress. J. Therm. Biol. 66:68-80. https://doi.org/10.1016/j .jtherbio.2017.03.014.

Dikmen, S., and P. J. Hansen. 2009. Is the temperature-humidity index the best indicator of heat stress in lactating dairy cows in a subtropical environment? J. Dairy Sci. 92:109-116. https://doi .org/10.3168/jds.2008-1370.

Eigenberg, R. A., J. A. Nienaber, and T. M. Brown-Brandl. 2003. Development of a livestock safety monitor for cattle. Paper no. 032338 in Proc. 2003 ASAE Annual Meeting. American Society of Agricultural and Biological Engineers. https://doi.org/10.13031/ 2013.13837.

Gaughan, J., J. Goopy, and J. Spark. 2002. Excessive heat stress index for feedlot cattle. Meat and Livestock Australia Ltd. project report, FLOT.316. https://data.globalchange.gov/assets/b8/55/ f775724c95e17c1b0fb971e0987e/FLOT.316.pdf.

Gaughan, J. B., S. M. Holt, G. L. Hahn, T. L. Mader, R. Eigenberg, and G. M. Stone. 2000. Respiration rate - Is it a good measure of heat stress in cattle? Asian Australas. J. Anim. Sci. 13:329-332.

Gaughan, J. B., and T. L. Mader. 2014. Body temperature and respiratory dynamics in un-shaded beef cattle. Int. J. Biometeorol. 58:1443-1450. https://doi.org/10.1007/s00484-013-0746-8.

Gaughan, J. B., T. L. Mader, S. M. Holt, and A. Lisle. 2008. A new heat load index for feedlot cattle. J. Anim. Sci. 86:226-234. https: //doi.org/10.2527/jas.2007-0305.

Gebremedhin, K. G. 2012. Heat stress and evaporative cooling. Chapter 3 (pages 35-48) in Environmental Physiology of Livestock. Wiley Online. https://onlinelibrary.wiley.com/doi/abs/10.1002/ 9781119949091.ch3.

Grömping, U. 2006. Relative importance for linear regression in R: the package relaimpo. J. Stat. Softw. 17:1-27. https://doi.org/10 $.18637 /$ jss.v017.i01.
Hahn, G. L., T. L. Mader, and R. A. Eigenberg. 2003. Perspective on development of thermal indices for animal studies and management. EAAP Tech. Ser. 7:31-44. https://doi.org/10.1002/rra.736.

Hales, J. R., and J. D. Findlay. 1968. Respiration of the ox: normal values and the effects of exposure to hot environments. Respir. Physiol. 4:333-352. https://doi.org/10.1016/0034-5687(68)90039 $-X$.

Havenith, G., and D. Fiala. 2015. Thermal indices and thermophysiological modeling for heat stress. Compr. Physiol. 6:255-302. https: //doi.org/10.1002/cphy.c140051.

Hernández-Julio, Y. F., T. Yanagi Jr., M. de Fátima Ávila Pires, M. Aurélio Lopes, and R. Ribeiro de Lima. 2014. Models for prediction of physiological responses of Holstein dairy cows. Appl. Artif. Intell. 28:766-792. https://doi.org/10.1080/08839514.2014.952919.

Igono, M. O., and H. D. Johnson. 1990. Physiologic stress index of lactating dairy cows based on diurnal pattern of rectal temperature. Biol. Rhythm Res. 21:303-320. https://doi.org/10.1080/ 09291019009360091.

Jiang, M., K. G. Gebremedhin, and L. D. Albright. 2005. Simulation of skin temperature and sensible and latent heat losses through fur layers. Trans. ASAE 48:767-775. https://doi.org/10.13031/2013 .18319.

Johnson, J. W., and J. M. LeBreton. 2004. History and use of relative importance indices in organizational research. Organ. Res. Methods 7:238-257. https://doi.org/10.1177/1094428104266510.

Kabuga, J. D. 1992. The influence of thermal conditions on rectal temperature, respiration rate and pulse rate of lactating Holstein-Friesian cows in the humid tropics. Int. J. Biometeorol. 36:146-150. https://doi.org/10.1007/BF01224817.

Kadzere, C. T., M. R. Murphy, N. Silanikove, and E. Maltz. 2002. Heat stress in lactating dairy cows: A review. Livest. Prod. Sci. 77:59-91. https://doi.org/10.1016/S0301-6226(01)00330-X.

Kendall, P. E., C. B. Tucker, D. E. Dalley, D. A. Clark, and J. R. Webster. 2008. Milking frequency affects the circadian body temperature rhythm in dairy cows. Livest. Sci. 117:130-138. https:// doi.org/10.1016/j.livsci.2007.12.009.

Kendall, P. E., and J. R. Webster. 2009. Season and physiological status affects the circadian body temperature rhythm of dairy cows. Livest. Sci. 125:155-160. https://doi.org/10.1016/j.livsci.2009.04 .004 .

Kuznetsova, A., P. B. Brockhoff, and R. H. B. Christensen. 2017. lmerTest package: Tests in linear mixed effects models. J. Stat. Softw. 82. https://doi.org/10.18637/jss.v082.i13.

Lee, C. N., K. G. Gebremedhin, A. Parkhurst, and P. E. Hillman. 2015. Placement of temperature probe in bovine vagina for continuous measurement of core-body temperature. Int. J. Biometeorol. 59:1201-1205. https://doi.org/10.1007/s00484-014-0931-4.

Mader, T. L., M. S. Davis, and T. Brown-Brandl. 2006. Environmental factors influencing heat stress in feedlot cattle. J. Anim. Sci. 84:712-719. https://doi.org/10.2527/2006.843712x.

Mader, T. L., L. J. Johnson, and J. B. Gaughan. 2010. A comprehensive index for assessing environmental stress in animals. J. Anim. Sci. 88:2153-2165. https://doi.org/10.2527/jas.2009-2586.

Maia, A. S. C., R. G. daSilva, and C. M. Battiston Loureiro. 2005. Sensible and latent heat loss from the body surface of Holstein cows in a tropical environment. Int. J. Biometeorol. 50:17-22. https://doi.org/10.1007/s00484-005-0267-1.

Martello, L. S., H. Savastano Junior, S. L. Silva, and J. C. C. Balieiro. 2010. Alternative body sites for heat stress measurement in milking cows under tropical conditions and their relationship to the thermal discomfort of the animals. Int. J. Biometeorol. 54:647652. https://doi.org/10.1007/s00484-009-0268-6.

McArthur, A. J. 1987. Thermal interaction between animal and microclimate: A comprehensive model. J. Theor. Biol. 126:203-238. https://doi.org/10.1016/S0022-5193(87)80229-1.

McGovern, R. E., and J. M. Bruce. 2000. AP-Animal Production Technology: A model of the thermal balance for cattle in hot conditions. J. Agric. Eng. Res. 77:81-92. https://doi.org/10.1006/jaer .2000 .0560 . 
Monteith, J., and M. Unsworth. 2013. Principles of Environmental Physics: Plants, Animals, and the Atmosphere. 4th ed. Academic Press/Elsevier, Amsterdam, the Netherlands.

NRC. 1971. A Guide to Environmental Research on Animals. National Academies Press, Washington, DC.

Reuter, R. R., J. A. Carroll, L. E. Hulbert, J. W. Dailey, and M. L. Galyean. 2010. Development of a self-contained, indwelling rectal temperature probe for cattle research. J. Anim. Sci. 88:3291-3295. https://doi.org/10.2527/jas.2010-3093.

Shiao, T. F., J. C. Chen, D. W. Yang, S. N. Lee, C. F. Lee, and W. Cheng. 2011. Feasibility assessment of a tunnel-ventilated, waterpadded barn on alleviation of heat stress for lactating Holstein cows in a humid area. J. Dairy Sci. 94:5393-5404. https://doi.org/ $10.3168 /$ jds.2010-3730.

Smith, T. R., A. Chapa, S. Willard, C. Herndon Jr., R. J. Williams, J. Crouch, T. Riley, and D. Pogue. 2006. Evaporative tunnel cooling of dairy cows in the Southeast. I: Effect on body temperature and respiration rate. J. Dairy Sci. 89:3904-3914. https://doi.org/ 10.3168/jds.S0022-0302(06)72433-X.

Sousa, R. V. D., T. F. Canata, P. R. Leme, and L. S. Martello. 2016. Development and evaluation of a fuzzy logic classifier for assessing beef cattle thermal stress using weather and physiological variables. Comput. Electron. Agric. 127:176-183. https://doi.org/10 .1016/j.compag.2016.06.014.

Spiers, D. E., J. N. Spain, M. R. Ellersieck, and M. C. Lucy. 2018. Strategic application of convective cooling to maximize the thermal gradient and reduce heat stress response in dairy cows. J. Dairy Sci. 101:8269-8283. https://doi.org/10.3168/jds.2017-14283.

Spiers, D. E., J. N. Spain, J. D. Sampson, and R. P. Rhoads. 2004. Use of physiological parameters to predict milk yield and feed intake in heat-stressed dairy cows. J. Therm. Biol. 29:759-764. https://do .org/10.1016/j.jtherbio.2004.08.051.
Thom, E. C. 1959. The discomfort index. Weatherwise 12:57-61. https: //doi.org/10.1080/00431672.1959.9926960.

Tresoldi, G., K. E. Schütz, and C. B. Tucker. 2018. Cooling cows with sprinklers: Timing strategy affects physiological responses to heat load. J. Dairy Sci. 101:11237-11246. https://doi.org/10.3168/jds 2018-14917.

Vickers, L. A., O. Burfeind, M. Von Keyserlingk, D. M. Veira, D. M. Weary, and W. Heuwieser. 2010. Comparison of rectal and vaginal temperatures in lactating dairy cows. J. Dairy Sci. 93:5246-5251. https://doi.org/10.3168/jds.2010-3388.

Wang, X., H. Gao, K. G. Gebremedhin, B. S. Bjerg, J. Van Os, C. B. Tucker, and G. Zhang. 2018. A predictive model of equivalent temperature index for dairy cattle (ETIC). J. Therm. Biol. 76:165170. https://doi.org/10.1016/j.jtherbio.2018.07.013.

West, J. W. 2003. Effects of heat-stress on production in dairy cattle. J. Dairy Sci. 86:2131-2144. https://doi.org/10.3168/jds.S0022 -0302(03) 73803-X.

Yano, M., H. Shimadzu, and T. Endo. 2014. Modelling temperature effects on milk production: a study on Holstein cows at a Japanese farm. Springerplus 3:129. https://doi.org/10.1186/2193-1801 $-3-129$.

Yousef, M. K. 1985. Stress Physiology in Livestock. 1st ed. CRC press, Boca Raton, FL.

\section{ORCIDS}

Gan Li ๑ https://orcid.org/0000-0002-0031-5841

Siyu Chen ำ https://orcid.org/0000-0002-5300-3649

Dandan Peng (ㄴ) https://orcid.org/0000-0002-4247-1535

Xianhong Gu ๑ https://orcid.org/0000-0002-2032-3179 